\title{
Photodynamic therapy in cancer treatment - an update review
}

\author{
Ancély Ferreira dos Santos, Daria Raquel Queiroz de Almeida, Leticia Ferreira Terra, Maurício S. \\ Baptista, Leticia Labriola
}

Department of Biochemistry, Chemistry Institute, University of São Paulo, São Paulo 05508-000, Brazil.

Correspondence to: Prof. Leticia Labriola, Department of Biochemistry, Chemistry Institute, University of São Paulo, São Paulo 05508-000, Brazil. E-mail: labriola@iq.usp.br; Prof. Maurício S. Baptista, Department of Biochemistry, University of São Paulo, Av. Prof. Lineu Prestes 748, São Paulo 05508-900, Brazil. E-mail: baptista@iq.usp.br

\begin{abstract}
How to cite this article: dos Santos AF, de Almeida DRQ, Terra LF, Baptista MS, Labriola L. Photodynamic therapy in cancer treatment - an update review. J Cancer Metastasis Treat2019;5:25. http://dx.doi.org/10.20517/2394-4722.2018.83
\end{abstract}

Received: 30 Nov 2018 First Decision: 22 Dec 2018 Revised: 1 Feb 2019 Accepted: 12 Feb 2019 Published: 29 Mar 2019

Science Editor: William P. Schiemann Copy Editor: Cai-Hong Wang Production Editor: Huan-Liang Wu

\begin{abstract}
Cancer remains a worldwide health problem, being the disease with the highest impact on global health. Even with all the recent technological improvements, recurrence and metastasis still are the main cause of death. Since photodynamic therapy (PDT) does not compromise other treatment options and presents reduced long-term morbidity when compared with chemotherapy or radiotherapy, it appears as a promising alternative treatment for controlling malignant diseases. In this review, we set out to perform a broad up-date on PDT in cancer research and treatment, discussing how this approach has been applied and what it could add to breast cancer therapy. We covered topics going from the photochemical mechanisms involved, the different cell death mechanisms being triggered by a myriad of photosensitizers up to the more recent-on-going clinical trials.
\end{abstract}

Keywords: Photodynamic therapy, breast cancer, photosensitizers, cell death

\section{INTRODUCTION}

Cancer remains a worldwide health problem. In particular, breast cancer is the disease with the highest impact on global health. Even with all the recent technological improvements, recurrence and metastasis still are the main causes of death. In fact, the high mortality as a consequence of distant metastasis in patients remains a bottleneck for an effective treatment in $\operatorname{clinic}^{[1,2]}$. Metastasis are characterized by a sequential and complex process during which cancer cells invade specific organs including lung, liver, brain, and bone ${ }^{[3]}$.

cC) (C) The Author(s) 2019. Open Access This article is licensed under a Creative Commons Attribution 4.0 International License (https://creativecommons.org/licenses/by/4.0/), which permits unrestricted use, sharing, adaptation, distribution and reproduction in any medium or format, for any purpose, even commercially, as long as you give appropriate credit to the original author(s) and the source, provide a link to the Creative Commons license, and indicate if changes were made.

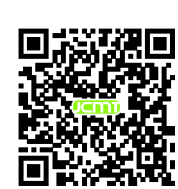


Metastatic lesions are usually multiple and resistant to conventional therapies, jeopardizing successful surgical resection, chemo and radiation treatment ${ }^{[4]}$.

Light has been known to provide a therapeutic potential for several thousands of years. Over 3000 years ago, since the Ancient, Indian and Chinese civilizations it has been used for the treatment of various diseases ${ }^{[5]}$ mainly in combination with reactive chemicals, for example to treat conditions like vitiligo, psoriasis and skin cancer ${ }^{[6]}$. After 1895 with the discovery of the phototherapy, which rendered Niels Ryberg Finsen the Nobel prize in Physiology/Medicine in 1903 in recognition of his work on the treatment of diseases, and in particular on the treatment of lupus vulgaris by means of concentrated light rays, many studies with the use of light and chemicals emerged ${ }^{[7]}$.

Photodynamic therapy (PDT) is currently being used as an alternative treatment for the control of malignant diseases $^{[8-10]}$. It is based in the uptake of a photosensitizer (PS) molecule which, upon being excited by light in a determined wavelength, reacts with oxygen and generates oxidant species (radicals, singlet oxygen, triplet species) in target tissues, leading to cell death ${ }^{[11,12]}$. PDT cytotoxic properties have been established to be due to the oxidation of a large range of biomolecules in cells, including nucleic acids, lipids, and proteins, leading to severe alteration in cell signaling cascades or in gene expression regulation ${ }^{[13,14]}$. Like all the newly proposed treatments, there is still place for improvements and lots of resources have been invested in this field recently. In this review, we set out to perform a broad up-date on PDT and it implication in cancer research and treatment. We have covered topics going from the photochemical mechanisms involved, the different cell death mechanisms being triggered by a myriad of photosensitizers up to the more recent reported preclinical studies and on-going clinical trials.

\section{PHOTOCHEMICAL PRINCIPLES AND COMPONENTS OF PDT}

As previously stated, PDT involves the photosensitized oxidation of biomolecules which can be separated in two mechanisms. In Type I, light energy passes from excited molecules to biomolecules through electron/ hydrogen transfer (radical mechanism) in direct-contact reactions [Figure 1] and culminates in specific damage to biomolecules and in the initiation of radical chain reactions. On the other hand, in the Type II mechanism, the excitation energy is transferred to molecular oxygen $\left({ }^{3} \mathrm{O}_{2}\right)$, resulting in the formation of singlet oxygen $\left({ }^{1} \mathrm{O}_{2}\right)$, which is extremely electrophilic, being capable of causing damage to membranes, proteins and DNA [Figure 1]. Direct contact reactions usually cause more severe damage in biomolecules, but also cause photodegradation of the PS, while diffusive species are important to replenish the PS. By either mechanism, the formation of triplet excited species is the key step in terms of performance of the PS. Both tricyclic phenotiazinium salts and macrocyclic poly-pyrroles (porphyrins and derivatives) compounds generate, reasonable amounts of triplets upon electronic excitation, being therefore PSs commonly used for $\mathrm{PDT}^{[15]}$. There is no doubt that the outcome of PDT critically depends on the intrinsic efficiency of the PS. Even when the search for new PS remains mostly focused in the synthesis of compounds that produce singlet oxygen with greater efficiency, there are many factors needed to be considered including aggregation and photodegradation ${ }^{[15]}$.

Damages to proteins and membranes are of particular importance for PDT in order to optimize the cytotoxic efficiency to the process. Indeed, PSs displaying a higher degree of accumulation in cell and/or organelles membranes are usually more cytotoxic ${ }^{[16,17]}$. The mechanism by which photosensitized oxidations on lipids cause membranes to leak out, has been recently described ${ }^{[18]}$. In generic terms, changes in phospholipids occur due to lipid peroxidation, which are reactions that are initiated as a consequence of the formation of free radicals and singlet oxygen. After this starting point, the process becomes autocatalytic, leading to the formation of hydroperoxides and other byproducts. Figure 2 summarizes the main steps in photo-induced membrane damage. The first one usually involves the "ene" reaction between the lipid (LH) 


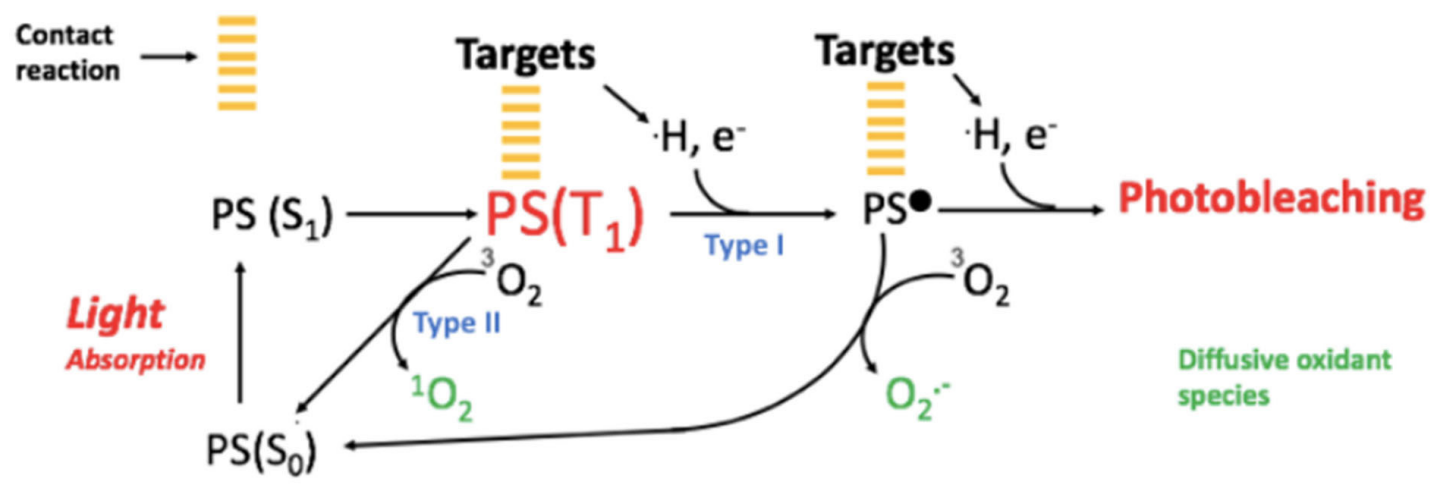

Figure 1. Mechanisms of photosensitization. The photosensitizer (PS), is a molecule capable to absorb energy from light in a specific wavelength. Once excited, the PS transits from its ground state PS $\left(\mathrm{S}_{0}\right)$, to its singlet excited PS $\left(\mathrm{S}_{1}\right)$ and triplet excited $\operatorname{PS}\left(\mathrm{T}_{1}\right)$ states. At this point $\mathrm{PS}\left(\mathrm{T}_{1}\right)$ can react directly with biomolecules, like proteins or lipids (targets), via Type I photochemical reaction, resulting in formation of radicals, like $\mathrm{PS}^{\circ}$, capable to initiate radical chain reactions. Otherwise, $\mathrm{PS}\left(\mathrm{T}_{1}\right)$ can react with molecular oxygen ${ }^{3} \mathrm{O}_{2}$, via the Type II photochemical reaction. Both generates diffusive oxidant species like radical superoxide, $\mathrm{O}_{2}{ }^{-}$, and singlet oxygen, ${ }^{\prime} \mathrm{O}_{2}$, via type I and II respectively, capable to extend the damage

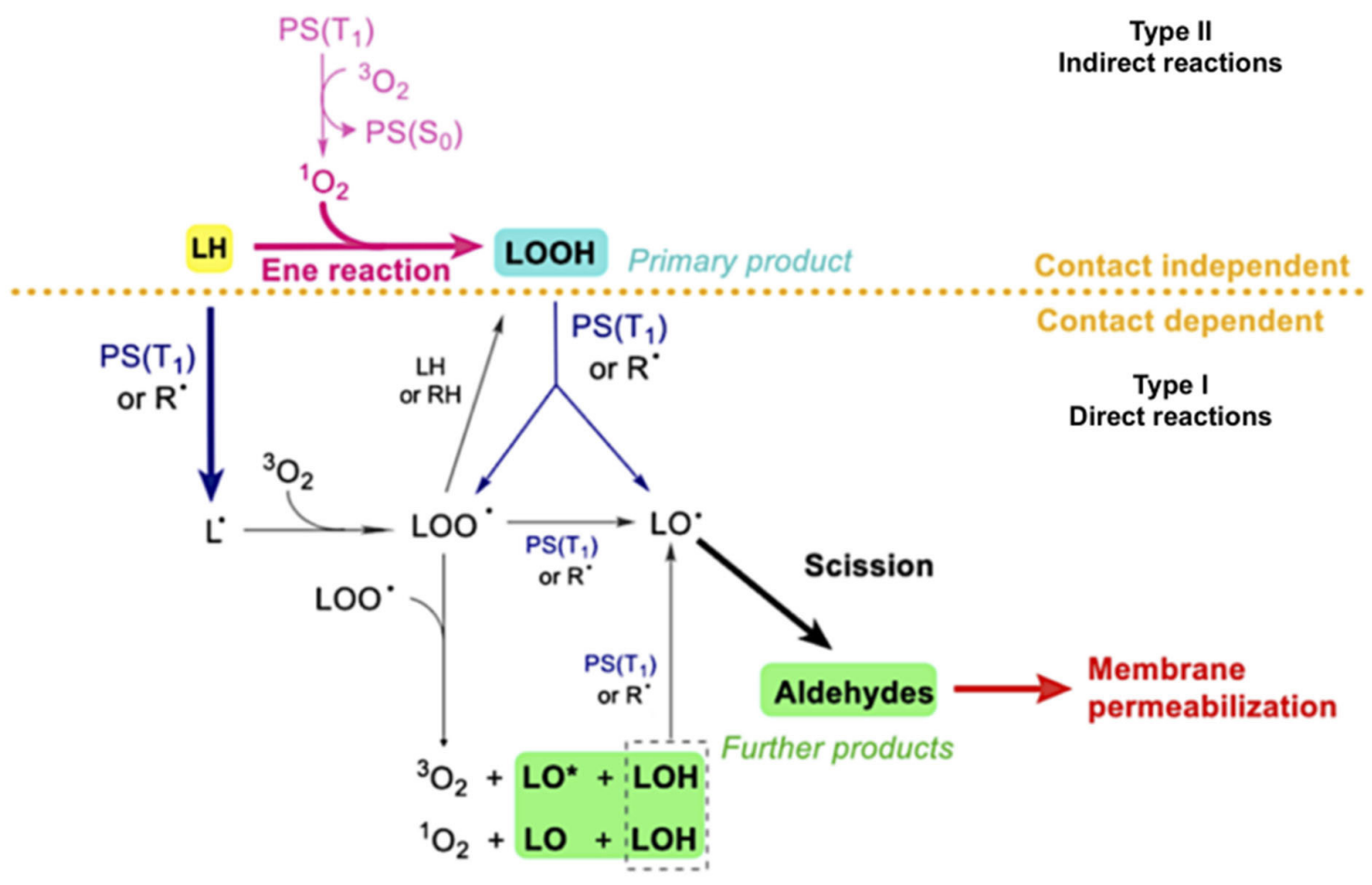

Figure 2. Mechanisms of photo-induced membrane damage. This graphical sketch represents how Type I and Type II photochemical reactions contribute to membrane leakage through lipid damage. Type I reactions lead to changes in membrane fluidity which occur as a result of direct-contact reactions between the PS triplet [PS $\left(\mathrm{T}_{1}\right)$ ] and either the lipid double bond of LH or the LOOH. Type II reactions [PS $\left(\mathrm{T}_{1}\right)$ and molecular oxygen $\left({ }^{3} \mathrm{O}_{2}\right)$ ] generates singlet oxygen $\left({ }^{1} \mathrm{O}_{2}\right)$ which leads to the formation of hydroperoxide ( $\left.\mathrm{LOOH}\right)$ as primary

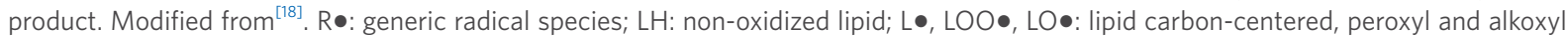
radicals; $\mathrm{LOOH}, \mathrm{LOH}, \mathrm{LO}, \mathrm{LO}^{*}$ : lipid hydroperoxide, alcohol, ketone and excited state ketone

and singlet oxygen (formed via type II photochemical reaction between PS triplet PS( $\left.\mathrm{T}_{1}\right)$ and molecular oxygen) leading to the formation of hydroperoxide ( $\mathrm{LOOH})$. The other steps comprise direct reactions with the PS $\left(\mathrm{T}_{1}\right)$ via Type I photochemical mechanism. Irreversible damage occurs with the abstraction of a hydrogen atom from an unsaturated fatty acid ( $\mathrm{LH})$, leading to the formation of a lipid radical (L•). This one suffers the addition of an oxygen molecule forming the peroxyl radical (LOO•) which is, in turn, able to react with another LH fatty acid, initiating a new oxidation round leading to the formation of lipid hydroperoxide 
(LOOH) and another L•. The propagation phase comprises the initiation of a new oxidation chain by the peroxyl radical (LOO•) and the decomposition of the lipid hydroperoxides into other intermediate radicals. In light-induced reactions, formation of alkoxides is catalyzed by direct contact reactions between the triplet photosensitizer, the lipid double bond and the lipid hydroperoxide, leading to chain breakage by -scission. This process leads to the formation of lipid truncated aldehydes and further products, which are molecules responsible for starting of the leakage process. This explains successful results as well as opens possibilities for cellular targeting strategies that will be discussed below.

\section{RESEARCH IN PDT}

\section{Photosensitizers and photocytotoxicity mechanisms}

The PS is one of the three crucial elements of PDT, apart from light and oxygen. Due to their photochemistry properties and uptake efficiency currently only a few PSs have official approval worldwide and are being used clinically. Related to cancer treatment, PS approved or in clinical trial are listed on Table 1. In particular, Porfimer sodium (Photofrin), mTHPC (Foscan), NPe6 (Laserphyrin), SnEt2 (Purlytin), Visudyne (Veteporfin) and Motexafin lutetium (LuTex) are clinically or preclinically applied for breast cancer ${ }^{[19-21]}$. These photosensitizers have shown selectivity towards tumor cells and are ideal for cellular and vascular-targeted PDT. Moreover their interference with cytoprotective molecular responses constitutes an area of growing interest ${ }^{[22,23]}$. Other compounds such as porphyrin precursors [e.g., aminolevulinic acid (ALA)] ${ }^{[24]}$, phenothiazines (e.g., methylene blue $)^{[25,26]}$, cyanines (e.g., merocyanine, indocyanine green $)^{[27]}$, hypericin ${ }^{[28]}$, and xanthenes (e.g., Rose Bengal ${ }^{[29]}$ have been considered as good candidates as PS used for PDT.

Several studies have been performed over the last decades in order to better characterize PS efficacy and selectivity. Some of them have focused on the development of agents with higher absorption wavelengths, allowing deeper penetration of illuminating sources and thus the depths at which tumor cells can be targeted, the so-called second-generation PSs. Third-generation PSs have recently emerged aiming mainly at targeting strategies, such as antibody-directed PS and PS-loaded nanocarriers. These approaches were developed in order to increase the power and efficiency of PDT and have allowed the broadening of the types of diseased tissues that could be treated ${ }^{[36]}$.

Besides the PSs photoactive capacity, which enables it as a therapeutic agent upon light activation, their autofluorescence is also an important characteristic. Indeed, PS's fluorescence confers them imaging properties to be used for detection of pre-cancer lesions and early malignancies, as well as tumor margins. Furthermore, this property can be used for the identification of remaining dysplastic tissue upon surgical tumor resections, and to monitor the progress of the PDT treatment. Thus the combination of imaging, detection and therapeutic properties confers them the characteristics of theranostic agents ${ }^{[36,37]}$. PS 5-ALA, which is a prodrug enzymatically converted during heme synthesis to the active PS agent protoporphyrin IX, displays theranostic properties and has brought important knowledge in PDT research and treatment field. Additionaly, in clinical trials 5-ALA has already shown clinical benefit in different types of tumors ${ }^{[24]}$.

PDT is considered to be involved in at least three main mechanisms of tissue destruction. The first one is the ability to directly kill cells through the action of damaging reactive chemical species generated by PS excitation. Direct phototoxic effect of PDT involves irreversible photodamage to specific targets, such as membranes and organelles ${ }^{[38]}$ as discussed in the previous section. The extent of the damage as well as the cell death mechanisms involved are dependent on the PS type, concentration, subcellular localization, energy applied and also on the intrinsic resistance characteristics of each tumor type. When perturbations of the intracellular and/or extracellular microenvironment are too intense, cells can die following a complete breakdown of the plasma membrane (necrosis morphology) or elicit specific cell death mechanisms ${ }^{[39]}$. Additionally, PDT tumor destruction can also involve the damage of the tumor vasculature, thereby 
Table 1. Photosensitizers investigated in clinical trial for cancer treatment ${ }^{[15,21,23,30-35]}$

\begin{tabular}{|c|c|c|c|c|}
\hline Photosensitizer & $\begin{array}{l}\text { Chemical } \\
\text { family }\end{array}$ & $\begin{array}{l}\text { Treatment } \\
\text { Wavelength } \\
(\mathrm{nm})\end{array}$ & Cancer type & Characteristics \\
\hline $\begin{array}{l}\text { Porfirmer sodium, HPD: } \\
\text { hematoporphyrin derivative } \\
\text { (Photofrin) }\end{array}$ & Porphyrin & 630 & $\begin{array}{l}\text { Lung, esophagus, } \\
\text { bile duct, bladder, } \\
\text { brain, ovarian, } \\
\text { breast skin } \\
\text { metastases }\end{array}$ & $\begin{array}{l}\text { 1st generation PS } \\
\text { Most probable intracellular localization: plasma } \\
\text { membrane and mitochondria. } \\
\text { Intravenous administration }\end{array}$ \\
\hline $\begin{array}{l}\text { 5-ALA: 5-aminolevulinic acid } \\
\text { (Levulan) }\end{array}$ & $\begin{array}{l}\text { Porphyrin } \\
\text { precursor }\end{array}$ & 630 & $\begin{array}{l}\text { Skin, bladder, brain, } \\
\text { esophagus }\end{array}$ & $\begin{array}{l}\text { 2nd generation PS } \\
\text { Most probable intracellular localization: mitochondria } \\
\text { Topical, oral or intravenous administration }\end{array}$ \\
\hline $\begin{array}{l}\text { MAL: methyl-aminolevulinate } \\
\text { (Metvix) }\end{array}$ & $\begin{array}{l}\text { Porphyrin } \\
\text { precursor }\end{array}$ & 630 & Skin & $\begin{array}{l}\text { 2nd generation PS } \\
\text { Most probable intracellular localization: mitochondria } \\
\text { and ER } \\
\text { Topical administration }\end{array}$ \\
\hline $\begin{array}{l}\text { h-ALA: hexylaminolevulinate } \\
\text { (Hexvix) }\end{array}$ & $\begin{array}{l}\text { Porphyrin } \\
\text { precursor }\end{array}$ & White light & Basal cell & $\begin{array}{l}\text { 2nd generation PS } \\
\text { Intracellular localization: TBD } \\
\text { Topical administration }\end{array}$ \\
\hline $\begin{array}{l}\text { Veteporfin, BDP: benzoporphyrin } \\
\text { derivative (Visudyne) }\end{array}$ & Porphyrin & 690 & Pancreas, breast & $\begin{array}{l}\text { 2nd generation PS } \\
\text { Most probable intracellular localization: mitochondria } \\
\text { Intravenous administration }\end{array}$ \\
\hline $\begin{array}{l}\text { Palladium bactereopheophorbide, } \\
\text { padeliporfin, WST-11 (Tookad) }\end{array}$ & Porphyrin & 762 & Esophagus, prostate & $\begin{array}{l}\text { 2nd generation PS } \\
\text { Intracellular localization: TBD. Intravenous } \\
\text { administration }\end{array}$ \\
\hline $\begin{array}{l}\text { Temoporfin, } \\
\text { mTHPC: meso- } \\
\text { tetrahydroxyphenylchlorine } \\
\text { (Foscan) }\end{array}$ & Chlorin & 652 & $\begin{array}{l}\text { Head and neck, } \\
\text { lung, brain, bile } \\
\text { duct, pancreas skin, } \\
\text { breast }\end{array}$ & $\begin{array}{l}\text { 2nd generation PS } \\
\text { Most probable intracellular localization: mitochondria, } \\
\text { golgi apparatus and ER } \\
\text { Intravenous administration }\end{array}$ \\
\hline $\begin{array}{l}\text { Talaporfin, mono-L-aspartyl chlorin } \\
\text { e6, NPe6, LS11 (Laserphyrin) }\end{array}$ & Chlorin & 660 & $\begin{array}{l}\text { Liver, colon, brain, } \\
\text { lung, breast skin } \\
\text { metastases }\end{array}$ & $\begin{array}{l}\text { 2nd generation PS } \\
\text { Most probable intracellular localization: Iysosomes } \\
\text { Intravenous administration }\end{array}$ \\
\hline $\begin{array}{l}\text { HPPH: } \\
\text { 2-(1-hexyloxyethyl)-2-devinyl } \\
\text { pyropheophorbide-a (Photochlor) }\end{array}$ & Chlorin & 665 & $\begin{array}{l}\text { Head and neck, } \\
\text { esophagus, lung }\end{array}$ & $\begin{array}{l}\text { 2nd generation PS } \\
\text { Most probable intracellular localization: mitochondria } \\
\text { and/or lysosomes } \\
\text { Intravenous administration }\end{array}$ \\
\hline $\begin{array}{l}\text { Rostaporfin, SnEt2: tin ethyl } \\
\text { etiopurpurin I, or (Purlytin) }\end{array}$ & Chlorin & 660 & Skin, breast & $\begin{array}{l}\text { 2nd generation PS } \\
\text { Most probable intracellular localization: Iysosomes } \\
\text { Intravenous administration }\end{array}$ \\
\hline $\begin{array}{l}\text { Fimaporfin, disulfonated tetraphenyl } \\
\text { chlorin, TPCS2a (Amphinex) }\end{array}$ & Chlorin & 633 & $\begin{array}{l}\text { Superficial cancers, } \\
\text { Cholon }\end{array}$ & $\begin{array}{l}\text { 2nd generation PS } \\
\text { Most probable intracellular localization: endo- } \\
\text { lysosomal compartments } \\
\text { Intravenous administration }\end{array}$ \\
\hline Motexafin lutetium (Lutex) & Texaphyrin & 732 & Breast & $\begin{array}{l}\text { 2nd generation PS } \\
\text { Broad intracellular localization } \\
\text { Intravenous administration }\end{array}$ \\
\hline
\end{tabular}

TBD: to be determined

compromising the supply of oxygen and essential nutrients, as well as activation of the immune system, by inducing an inflammatory and an immune response against tumor cells ${ }^{[23,35,40]}$.

Cell death subroutines are strongly connected with successful therapy outcome. Even when a detailed explanation of cell death mechanisms is not the scope of this review (updated and deeper information can be assessed $i^{[39]}$ ), here we point some of their important features, since describing one or ones of them involved in cell toxicity constitutes a very important topic of research in the field of PDT.

At the cellular level, PDT has been shown to induce multiple cell death subroutines, that can be accidental or not [Figure 3]. Accidental cell death is an uncontrollable form of death corresponding to the physical disassembly of the plasma membrane caused by extreme physical, chemical, or mechanical cues. On the other hand, regulated cell death (RCD) results from the activation of one or more signal transduction modules, and hence can be pharmacologically or genetically modulated, at least to some extent ${ }^{[39]}$. The RCD subroutines already related with PDT include apoptosis and different mechanisms of regulated necrosis 


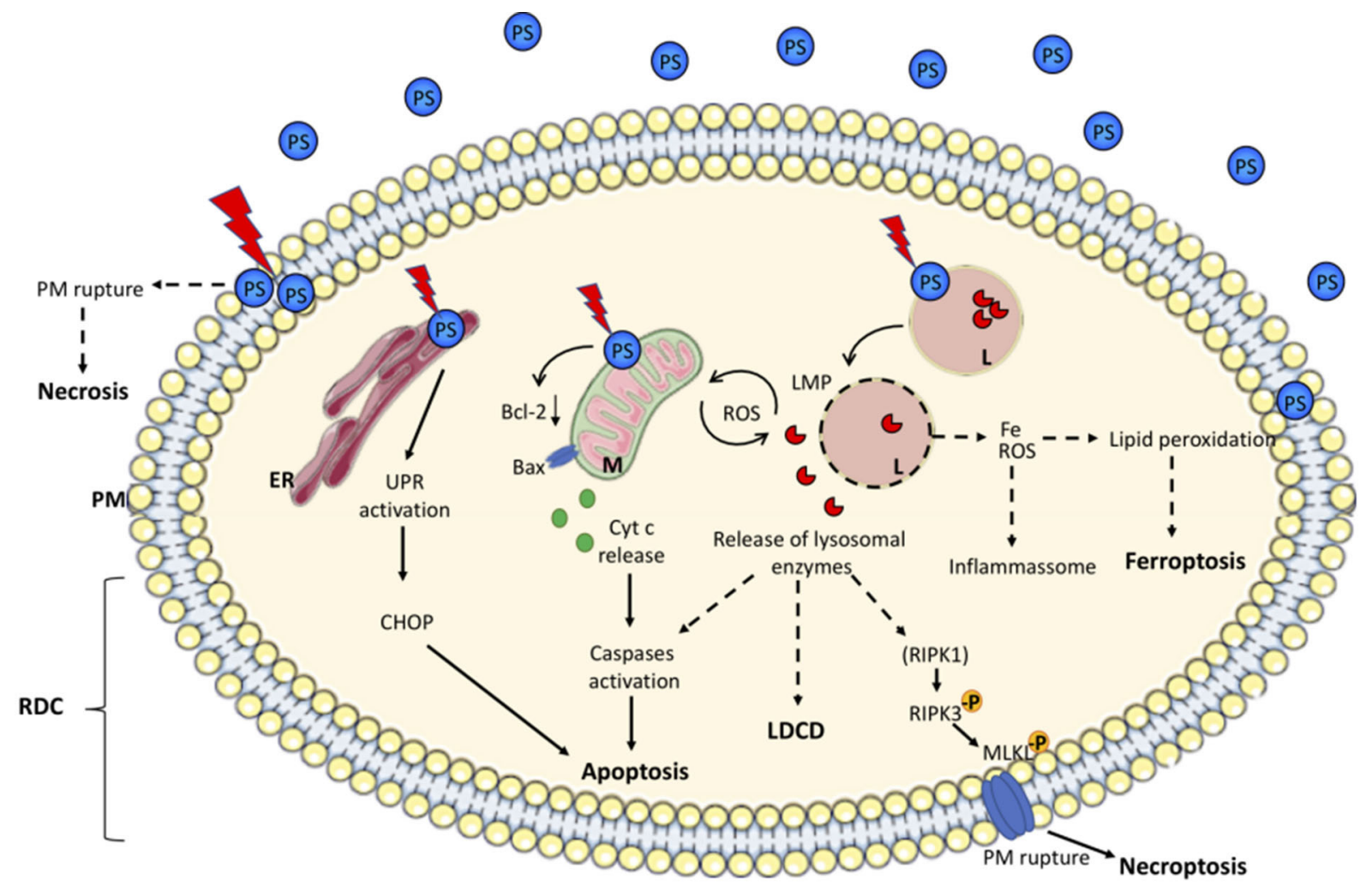

Figure 3. Overview of cell death subroutines that can be elicited by Photodynamic therapy. The most described locations of different photosensitizers (PS) are the plasma membrane (PM), endoplasmic reticulum (ER), mitochondria (M) or the lysosome (L). Depending on its localization, after activation by light (red lightinhbolt) it can directly damage the PM causing unregulated necrosis or culminate in one or more regulated cell death (RCD) mechanisms. UPR: unfolded protein response; LMP: lysosome membrane permeabilization; Fe: iron; ROS: reactive oxygen species; -P: phosphate group presented in the active forms of RIPK3 and MLKL on necroptosis pathway; LDCD: lysosomal dependent cell death

(such as necroptosis and lysosome-dependent cell death) ${ }^{[15,41]}$. Briefly, apoptosis ${ }^{[42]}$ is a type of RCD initiated by perturbations of the extracellular or intracellular microenvironment, being respectively classified as extrinsic (when signals are detected by plasma membrane receptors, and propagated by caspase- 8 and precipitated by executioner caspases, mainly caspase-3) or intrinsic (demarcated by mitochondrial membrane permeabilization (MOMP), unbalance of pro and anti-apoptotic factors related with members of BCL2 family of proteins, and precipitated by the executioner caspases $)^{[39,43-48]}$. Necroptosis is a modality of RCD triggered by perturbations of extracellular or intracellular homeostasis that critically depends on phosphorylation, oligomerization and migration of MLKL (mixed lineage kinase domain-like protein) to plasma membrane, the kinase activities of RIPK3 and (at least in some settings) of RIPK1 (receptor interacting protein kinases-1 and -3 , respectively) ${ }^{[49]}$. Finally, lysosome-dependent cell death (LDCD) is a consequence of lysosomal membrane permeabilization ${ }^{[50,51]}$ and releasing of cathepsins, with optional involvement of MOMP and caspases. Indeed, one of the advantages of PDT is that this therapeutic approach has demonstrated to be able to cope with the very well described ability to bypass the several resistance mechanisms displayed by malignant cells ${ }^{[26]}$.

PS localization within or on the cell surface is critical to determining the mode of cell death induction and thus the cellular response to photodamage ${ }^{[38,52,53]}$. Therefore, precise understanding of the preferential subcellular site of PS accumulation is important in order to determine its cytotoxic potential when used in $\mathrm{PDT}^{[38,54]}$. PS uptake by the tumorigenic cells as well as its preferential intracellular site depends on chemical characteristics of each compound. Hydrophobic molecules can rapidly diffuse into plasmatic membranes while more polar drugs tend to be internalized via endocytosis or assisted transport by serum lipids and 
proteins. After internalization, most of the PSs are localized in organelle membranes due to their common chemical core. In general, PS's cellular localization can be highly specific or quite broad, and have been reported to include the endoplasmic reticulum (ER), mitochondria, Golgi complex, lysosomes and the plasma membrane ${ }^{[40,55]}$. To limit DNA damage and avoid the development of genetically resistant cells, PS should not accumulate in the cell nuclei ${ }^{[30]}$. Accidental necrosis is more often observed when the PS site of action is in the plasma membrane and/or when it is activated with high energy doses ${ }^{[40]}$. In order to suppress undesired damage to normal tissues, this effect should in general be avoided ${ }^{[56]}$. In an organelle-specific photodamage scenario, the mechanism of autophagy is activated as a coordinated intracellular response aiming at reestablishing homeostasis. When impaired or insufficient autophagy is triggered, induction of cell death is the most common result observed ${ }^{[26,38,57,58]}$. The best documented organelle specific cytotoxic effects of PDT are related with the photodamage of mitochondria, lysosomes and ER.

Porphyrins can present a variable localization pattern, mostly associated with plasma membranes and mitochondria. PSs that are located in the mitochondria can cause mitochondrial inner membrane permeabilization and selectively damage antiapoptotic proteins of the BCL-2 family, localized at the outer mitochondrial membrane while the proapoptotic proteins are left intact, resulting in an unbalance of proand anti-apoptotic players that results in caspase activation ${ }^{[35]}$. On the other hand, some mitochondriaassociated porphyrins can also activate necroptosis, as already shown in 5-ALA-PDT ${ }^{[59]}$. A lysosome localization pattern was observed using negatively-charged porphyrins, NPe6 and the phenothiazinium methylene blue $e^{[26,38,53]}$. A potential advantage of lysosome target PDT is that lysosomal damage might easily circumvent autophagic protection that can be activated in parallel of cell damage. Lysosome damaging PDT leads to $\mathrm{LDCD}^{[39,51,60]}$. Release of cathepsins after PDT can result in cleavage of the pro-apoptotic protein Bid to a truncated form termed $\mathrm{tBid}$. This product can in turn interact with mitochondria, leading to the release of cytochrome $\mathrm{c}$, followed by the consequent activation of intrinsic apoptosis as already shown in NPe6$\mathrm{PDT}^{[41]}$. However, not only apoptosis can be activated by lysosome damage and although it has not been demonstrated as a PDT-induced mechanism yet, several parameters of regulated necrosis have been also associated with LDCD. Indeed, the degradation of caspase- 8 and recruitment of necroptosis machinery ${ }^{[61]}$ or even the involvement of iron homeostasis modulation leading to an increased susceptibility to undergo ferroptosis ${ }^{[62]}$ have already been associated with lysosomal damage. Other porphyrins such as mTHPC and Hypericin, have been reported to target ER or both ER and mitochondria. Under massive photodamage in ER membranes, PDT can elicit pro-death signaling via the unfolded protein response cascade. The resulted ER stress, activates the pro-apoptotic transcription factor $\mathrm{CHOP}$, which in turn mediates mitochondrial apoptosis $^{[63]}$. The induction of multiple cell death pathways is usually considered as an useful characteristic of PDT, since it increases photokilling in tumor cells harboring a particular cell death pathway resistance ${ }^{[64]}$.

\section{PDT and immune response as a tool to deal with metastasis}

The major challenge in the fight against cancer includes treatment toxicity and drug-resistance associated with incompletely tumor removal by surgical resection. In order to extend patient survival, systemic chemotherapy has become an essential part of treatment after surgery. However, therapies effective in both reducing the high mortality rate associated with the disease as well as improving patient quality of life still need to be developed ${ }^{[22,35]}$. In an attempt to circumvent the appearance of a secondary disease, immunotherapy has been applied and developed as a tool to control cancer recurrence and metastases. There are few effective treatments for metastases, thus there is an increased interest in therapies that eliminate primary tumors and systemically activate antitumor immune responses. In this sense, PDT emerges as a potential therapy to be used alone or in combination with other approved or experimental approaches ${ }^{[65]}$ because of the recent findings indicating that PDT can also trigger systemic effects, including the reinstallation of immunosurveillance ${ }^{[29,66]}$.

Examples of immunotherapy include the use of monoclonal antibodies to block immune checkpoint activity of cancer cells, enabling anti-cancer $\mathrm{T}$ cell responses, or adoptive cellular therapy to prime patient's own 
lymphocytes to attack cancer cells. The goal of immunotherapy is to generate a robust immune response, stimulating the endogenous cytotoxic lymphocytes to eradicate tumor cells and ultimately achieve longterm anticancer immunity ${ }^{[67]}$. Therefore, the ideal cancer treatment should involve the direct cytotoxic action on tumor cells with potential to stimulate the immune system based on the immune-recognition of danger signals emitted by dying cells ${ }^{[68]}$. In a typical immune response, antigens are captured by dendritic cells (DCs), which then mature and present antigenic peptides to T cells in lymph nodes, generating effector $\mathrm{T}$ cells that migrate towards sites of infection, inflammation or injury. IFN- $\gamma$ and GM-CSF are central to the process of DC maturation and macrophage activation. DCs in turn release cytokines, like IL-1 $\beta$, IL-6, IL12 or TNF, that shape the Natural Killer cell (NK) and T cell responses. T cells CD4+ and CD8+, together with NK cells, can receive survival signals and stimulation from IL-2, leading to full effector activities, and produce additional IFN- $\gamma$. Normal immune regulation involves cytokines like IL-10 and TGF- $\beta$ to limit the activity of $\mathrm{T}$ cells and macrophages and reduce inflammation, terminating immune responses and protecting the host from immune-mediated damage ${ }^{[67]}$. Some tumors appear to have somehow managed to avoid detection by the various arms of the immune system or have been able to limit the extent of immunological killing, thereby evading their eradication ${ }^{[69]}$.

The best way to reestablish an immune system response against tumors is by eliciting, therapeutically, a cancer cell death pathway that is accompanied by high immunogenicity and is possibly able to inhibit or reduce the influence of the pro-tumorigenic cytokine signaling. Over the last years, several studies demonstrated that few selected anti-cancer therapeutic approaches are able to induce a promising kind of cancer cell demise called immunogenic cell death (ICD $)^{[70]}$. The concept of ICD has been introduced to describe a cell death modality that stimulates an immune response against antigens coming from dead cells. After exposure to certain cytotoxic ICD-agents, changes in the composition of the cell surface promote the exposure or release of mediators, the so-called damage associated molecular patterns (DAMPs) ${ }^{[71]}$. These signals are thus further recognized by DCs to stimulate the presentation of tumor antigens to $\mathrm{T}$ cells $\mathrm{s}^{[72]}$. It has emerged that initiating a tumor cell death modality associated with the activation of signaling pathways that release DAMPs markedly increases the immunogenicity of dying cancer cells ${ }^{[73]}$. Up to now, the main DAMPs involved in ICD include surface-exposed calreticulin (CRT), surface-exposed heat shock protein (HSP) 70 and 90, secreted adenosine triphosphate and passively released high-mobility group box 1 (HMGB1 $)^{[1,74]}$. Many conventional anticancer treatments, that include chemotherapies, radiotherapies and target therapies have had their immunogenic potential evaluated, but only a few of them have been characterized as ICDinducers $^{[72]}$. This exclusive inducer-induction relationship exists because ICD requires, as a pre-requisite, induction of reactive oxygen species (ROS)-based ER stress, where ROS may or may not be mainly ERdirected $^{[75]}$. As a ROS-inducer therapy, the potential of PDT in stimulating ICD seems to be quite probable, and has been tested.

Preclinical studies have shown that in contrast to the effects of traditional therapies, low-dose PDT regimens can induce anti-tumor immunity, and these can be combined with high-dose PDT to achieve local tumor control with the immune suppression of distant disease ${ }^{[76]}$. The potential mechanisms of PDT immune stimulation involve the acute inflammatory response following PDT, which might increase the presentation of tumor antigens to activate DC, and their homing in to regional and peripheral lymph nodes, thus ultimately stimulating CD8+ cytotoxic T cells and NK cells, accompanied by immune memory and the suppression of any subsequent tumor growth upon a second challenge. The degree of acute inflammation induced by PDT has been reported to be regimen dependent and to correlate with the extent of the induced vascular damage. PDT regimens that result in rapid cell death (within $1 \mathrm{~h}$ of treatment) and maximal tissue damage were demonstrated to cause minimal acute inflammation, presumably because of vascular shutdown, which would prevent neutrophil infiltration and systemic release of cytokines. In contrast, regimens that cause diffuse tumor damage should allow neutrophil infiltration followed by induction of expression and release of inflammatory mediators critical for enhancement of anti-tumor immunity ${ }^{[7]]}$. Ongoing studies are focused 
on finding optimal PDT conditions to induce systemic immunity. Recent reports have shown that PDT can be an effective adjuvant therapy to surgery that increases the probability of long-term local disease control ${ }^{[30]}$. Recently results from a preclinical study have also identified an anti-tumor combined PDT treatment regimen that controls primary and metastatic tumor growth and enhances anti-tumor immunity of both colon and mammary carcinomas ${ }^{[76]}$. Recently, PDT utilizing the photosensitizer hypericin (Hyp-PDT), became the first PDT modality characterized as capable of inducing $\mathrm{ICD}^{[28]}$. Although the immunogenic potential has not been tested for all PS yet, these recent findings with hypericin constitute an important achievement because they have allowed PDT to be classified as a therapy capable of inducing ICD. Accordingly, a recent study have shown that glycoconjugated chlorin-PDT suppressed colon rectal tumor cells (CT26) growth more efficiently in immunocompetent mice compared with immuno-deficient mice. Additionally, the exposure of the mice to PDT-treated CT26 cells was capable of protecting them against a subsequent challenge with CT26 cells and this immunogenic effect was dependent on CRT exposure in the plasma membrane and HMGB1 release, two known features of $\mathrm{ICD}^{[65]}$. Moreover, the increased interest in PDT has actually helped in a deeper understanding of technical as well as conceptual aspects of ICD and the danger signals involved in this type of cell death. Further clinical research may perhaps point PDT as a method of vaccination against tumors ${ }^{[78,79]}$. This clearly would be of great advantage since PDT in patients treated for primary breast cancer could also result in increasing acquired immunity against the cancer at distant sites.

Overall, accumulating evidence indicates that the therapeutic efficacy of several antineoplastic agents, including PDT, relies on their capacity to influence the tumor-host interaction, tipping the balance toward the activation of an immune response specific for malignant cells, especially for metastasize cancer.

\section{Instrumentation, drawbacks and side effects}

PDT has been shown to be effective in treating different types of cancers, especially the ones with superficial localizations, as this intervention provides a significant improvement in both the patient's quality of life ${ }^{[80]}$ and its cost-effectiveness compared to palliative surgery or palliative chemotherapy treatments ${ }^{[81]}$. However, as happens with other therapies as well, the predominant unfavorable anatomical and microenvironment conditions have been reported to limit its efficacy and to contribute for the relatively slow transition from preclinical to clinical practice of PDT for treating these tumors ${ }^{[82,83]}$. Adjustment of PDT parameters such as type and local concentration of the PS, light delivery and source or dosimetry in a context where there is no homogeneity is considered as one of the bigger obstacles of this therapeutic approach ${ }^{[84]}$.

The most common concern about the clinical use of PDT constitutes the limited penetration of light. However, nowadays this old idea that PDT is as a surface treatment because the application of external light may only treat superficial lesions is no longer believed. This problem is actually in the way of being solved because of the possibility of using fibers which can be placed in determined locations within the tumor site. Due to advances in fiber optics and microendoscopic technology, PDT can be used in the clinic with interstitial, endoscopic, intraoperative or laparoscopic light delivery systems. In this scenario, the laser light can be adapted into thin optical fibers for delivery of light into deeper and more difficult to access treatment sites $^{[85]}$. These fibers besides being used to deliver light, can also simultaneously act as diagnostic sensors that can gauge important PDT parameters which critically impact the therapeutic response, such as the fluence rate, PS concentration, PS photobleaching and the tissue oxygenation status ${ }^{[86,87]}$. It is important to take into account that the vascular collapse promoted by PDT can decrease the tumor oxygenation. Since the success of the treatment relies on the preexisting ground state oxygen to produce singlet oxygen via type II photochemical reaction [Figure 1], tissue oxygenation state significantly affects the efficiency of PDT. Moreover during the treatment itself, the formation of ROS using high light fluence rates can deplete the oxygen levels in tumorigenic tissue too fast, aggravating the tumor hypoxia and hampering the treatment outcome ${ }^{[40,88,89]}$. Thus, improvement the oxygen concentration is an important issue for PDT. In fact, adjusting the light and PS dosimetry, lowering light fluence rates or using light fractionated strategies 
can prevent oxygen depletion and allow sufficient time for the replenishment of oxygen in the target tissue. However, it has already been reported that different PS affect the oxygen consumption rates differently ${ }^{[90]}$ and thus PDT outcome may vary. Altogether, these results point to the need of more studies addressing how to maintain PDT performance. An interesting study employing a combination of the fractionated PDT with a PS that could produce singlet oxygen during the dark periods ${ }^{[91]}$ has recently addressed this issue. Moreover, the presence of pre-existing hypoxic areas in tumors can be circumvented by a variety of strategies such as improving tissue oxygenation prior to PDT as well as by efficiently producing radical species via type I photochemical reactions ${ }^{[88]}$.

Regarding light source technology, researchers have been developing light delivery systems with uniform illumination, which is essential to improving light penetration and reproducibility. An example of this is the use of bulb-shaped isotropic emitters along with light detectors which have been used in hollow organs. Light dosimetry can also help to optimize the positioning of light diffusers. Furthermore, increasing the selectivity of PDT could be achieved by customizing the diffusers such as balloons and cylindrical applicators according to the form and dimensions of the target tissue ${ }^{[92,93]}$.

Additionally, recent advances in LED and diode lasers have allowed to merge their ability of output potency, enhanced portability and precision optical fiber coupling. These, non-collimated and less expensive light sources will certainly ease the translation of PDT to clinical procedures. They are usually employed due to their robustness, short bandwidth, relatively low maintenance cost and ability to be configured to the wavelength required by the PS. Lamps such as Tungsten filament lamps, metal halide lamps, powerful Xenon arc lamps and pulsed lasers are also commonly used in the PDT field ${ }^{[92]}$.

Besides the light source itself, defining the strategy of light application is of fundamental importance since different irradiation protocols using the same source can lead to different outcomes in PDT. Another drawback to be dealt with in PDT prescriptions is light dose regimens because they might also influence the host anti-tumor reactions and optimal strategies are likely case dependent ${ }^{[35,85]}$. Therefore, a full understanding of light dosimetry is an important part of PDT. The issue of light in PDT is under careful investigation and improvements and new technologies in this field will certainly lead to optimized overall PDT efficacy and protocols ${ }^{[94]}$. For example, one strategy to induce deep tissue phototoxicity is to perform repeated PDT or metronomic PDT (slow infusion of PS and low dose light) ${ }^{[95]}$. Recent studies have shown that fractionated PDT might induce a high degree of necrosis deeper than PDT alone ${ }^{[35,84,94]}$. The fact that this strategy may allow for continuous accumulation of PSs at the treatment site contributed to providing a better treatment response profile and increased the feasibility of reaching deeper tissues ${ }^{[84]}$.

In terms of adverse events associated with PDT, the most common is skin photosensitivity, especially when PSs of the first generation were systemically administered. In these cases, patients have to avoid sunlight and strong artificial light for weeks ${ }^{[21]}$. Another side effect often reported is pain ${ }^{[35]}$. The main mechanism behind PDT-induced pain has not yet been elucidated, but several studies have found it to be associated with the size of the treated area, PS type, lesion type, gender, age and light protocol. There are evidences suggesting that continuous activation of low levels of PS with methods using lower irradiance and possibly shorter incubation times are associated with decreased pain without loss of PDT efficacy ${ }^{[96]}$. Additionally, the occurrence of inflammation, fever and nausea are typical but often successfully managed with medication. Tumor recurrence is often reported in clinical trials, probably due to inadequate tumor eradication. It can be a result not only to insufficient light or PS penetration, but also the presence of PDT resistant tumors. Although the causes for recurrence often lie beyond the scope of clinical trials, there is a strategy to overcome incomplete tumor elimination by PDT that is to combine two or more PSs. The idea behind this is to choose PSs that target different cellular compartments of the tumors allowing for a better overall 
therapeutic outcome ${ }^{[64,95,97]}$. Another strategy could be to associate PDT with other existing compounds used for chemotherapy. In a recent study the combined use of ferroptosis inductors and Gencitabine has shown to be able to significantly overcome the resistance to the chemotherapeutic agent displayed quiet frequently in pancreatic adenocarcinomas ${ }^{[98]}$.

\section{PDT in preclinical models of invasive cancer: an up-dated report}

Most people diagnosed with cancer will require surgery as the main strategy for tumor removal with or without radiotherapy and systemic therapy. Tumor cells generally migrate from a primary tumor through the blood stream and lymphatic system and may be detected in one or more sentinel lymph nodes before spreading further to a secondary site. In the case of non-metastatic cancer, identifying cancer cells in the lymph nodes is one of the most important prognostic factors for determining the need for adjuvant radiation therapy and/or chemotherapy. Once cancer has spread to distant sites, the removal of tumor has not consistently shown a survival benefit. In these cases, surgery may help with palliative control of an ulcerated tumor on the chest wall and only unspecific broad-spectrum therapies are the currently treatment option available $^{[99]}$. Thus, effective and safe therapies for this stage of the disease are still needed.

Several in vitro studies have shown a synergism between PDT and ionizing radiation in killing cells ${ }^{[100,101]}$. The combined application of low dose of radiotherapy (4Gy) and indocyanine green, with light proved to be very effective and resulted in a nearly complete reduction of survival ${ }^{[101]}$. In a preclinical animal model, PDT following radiotherapy showed evidences of improved trabecular structure. Quantitative histological examination suggested that PDT induced increases in the bone-to-marrow ratio, due mainly to the increased formation of newly formed woven bone and an increase in osteoid formation in comparison with the situation in rats treated with radiotherapy alone ${ }^{[102]}$. A subsequent study demonstrated that PDT appeared to improve vertebral integrity in combination with bisphosphonates or radiotherapy ${ }^{[103]}$, suggesting its potential use in adjuvant treatment of spinal metastases. These reports suggest that treatment of tumors with a combination of PS-mediated PDT and ionizing radiation could be superior to their individual use. The interaction of PDT and ionizing radiation could enhance the systemic therapeutic effect, thus reducing the radiation dose and potential side effects.

The effect of PDT combined with traditional chemotherapy for the treatment of breast cancer has also been studied and there are many examples. The treatment with appropriately combined low doses of cisplatin and indocyanine green- based PDT in vitro was proven to be more effective than each therapy alone ${ }^{[104]}$. This synergistic effect is of extreme importance to be considered since cisplatin is one of the chemotherapeutics which is likely to cause severe side effects. Also the combination of mTHPC mediated PDT and 5-fluoro-2-deoxyuridine resulted in lower cell survival than the corresponding single mode treatment ${ }^{[105]}$. Additionally, the enhanced antitumor effects between PDT and doxorubicin has already been demonstrated both in vitro ${ }^{[106]}$ and in vivo ${ }^{[107]}$ in a preclinical study on breast cancer. Although little is known about the mechanisms involving the interactions between chemotherapeutic drugs and PSs, or how they can be combined to increase cell killing and reducing side effects, all the cooperative effects between PDT and traditional chemotherapeutics cannot be neglected. Hence, PDT in combination with chemotherapy is among many strategies which have been proposed to potentiate the therapeutic outcome of low-dose chemotherapy and thus minimize side effects and acquisition of drug resistance ${ }^{[35]}$. A great advantage of PDT is that it can be used either before or after chemotherapy, radiotherapy or surgery, without compromising these therapeutic modalities. Moreover, the adverse effects of chemotherapy or radiation do not affect sensitivity to PDT ${ }^{[35]}$. These findings support the use of PDT, at least as an adjuvant therapy, for enhancement of anti-tumor immunity which may be capable of controlling cancer secondary disease.

Further research and more effort are required in order to allow PDT to be accepted as a suitable treatment for breast cancer. Even though, there is lot of evidence pointing that this therapeutic approach should 
be considered as an antitumor treatment, the actual challenge for PDT is to translate the advances in understanding the effects in the cell-line-based and animal models studies into the clinical practice.

\section{Clinical applications of PDT; Combination with other therapies; On-going trials}

Despite the increasing number of studies with a growing number of chemical compounds and their generally increased number of favorable aspects as compared to more standard treatments, only a few PS have already been approved for clinical use and only for the treatment of a few diseases.

While the majority of PDT uses involve different types of cancer, ALA use with distinct formulations is already approved for several clinical applications, ranging from mild and moderate actinic keratosis to nonhyperkeratotic actinic keratosis. Some are also used to treat the Bowen's disease and basal cell carcinoma ${ }^{[40]}$. Moreover, for serious ocular diseases such as age-related macular degeneration and myopic choroidal neovascularization there is a clinically approved PS called Verteporfin in current use ${ }^{[108,109]}$. In 1993, Porfimer sodium (Photofrin) was the first PS approved for clinical used of PDT by the Canadian Health Agency for bladder cancer treatment. Later on, it was approved by the Food and Drug Administration (FDA) and also in several other countries for the treatment of various types of cancer, such as lung, esophageal, gastric, and cervical cancers as well as for cervical dysplasia ${ }^{[110]}$. This photosensitizer is still widely used in PDT for treatment of various conditions ${ }^{[111,112]}$. However, being a complex mixture of molecules with poor tissue selectivity and low light absorption, high concentrations of porfimer sodium are needed, which make it to persist over 2 months after the administration ${ }^{[113]}$, rendering patients photosensitive ${ }^{[114]}$. A secondgeneration of PS has been then developed, with improved purity, longer wavelength absorptions and higher photosensitivity and tissue selectivity. Temoporfin was the second PS to receive approval and extensively used for treatment of advanced head and neck squamous cell carcinomas ${ }^{[115,16]}$. Temoporfin was also tried for the treatment of breast, pancreatic and prostatic cancer ${ }^{[117-121]}$, with mixed results. For breast cancer there was response in all patients with minimal-invasive and few side effects ${ }^{[119]}$. Similarly, for prostate cancer it appeared a safe procedure and after 8 of 10 PDT sessions, the prostate specific antigen fell by up to $67 \%$ and biopsies of treated areas revealed necrosis and fibrosis at 1-2 months ${ }^{[120]}$. However, in patients with malignant biliary obstruction, endoscopically delivered Temoporfin-PDT caused efficient tumor necrosis and recanalization of blocked metal stents, but it showed a significant risk of complication with one leading to a fatal liver abscess and two patients developing haemobilia within 4 weeks of treatment, one of whom died with a gall bladder empyema ${ }^{[118]}$. A mono-L-aspartyl chlorin, Talaporfin, was approved in Japan as a PDT for lung cancer but was also employed for early head and neck cancer patients and is going through the phase II trial for the treatment of colorectal neoplasms and liver metastasis ${ }^{[122]}$. There are also other drugs approved as orphan drugs by the FDA for PDT treatment for Cutaneous T-cell lymphoma (SGX301) and for biliary tract cancer $\left(\mathrm{LUZ}_{11}\right)^{[40]}$.

Since PDT has the potential to present a local effect, it lacks systemic adverse effects seen in other therapies. Additionally, because of its mechanism, PDT can be used in the clinic in combination with other procedures, such as radiotherapy, chemotherapy or surgery. At the present time there are a number of on-going trials using PDT with distinct PS for different types of cancer. Among all the on-going trials registered at clinicaltrials.gov (not concluded), about 50\% of them use PDT alone or in combination with other therapies for at least one condition [Table 2]. So far PDT using distinct photosensitizers appears to be effective in decreasing tumor size and increasing patient survival in several of the trials, which target different kinds of tumors [Table 3]. Interestingly, the clear majority of current on-going trials for cancer are using photosensitizers that have already been approved for clinical use, mainly with Photofrin and ALA but also with Verteporfin and other still unapproved compounds.

The majority of approved PDT protocols are related to the treatment of superficial lesions of skin and luminal organs. However, due the enhancement of PS efficiency and light delivery, interstitial and intra- 
Table 2. Number of on-going trials registered in clinicaltrials.gov using Photodynamic therapy for major conditions

\begin{tabular}{lc}
\hline Major condition & Number of trials \\
\hline Cancer & 49 \\
Dermatological diseases & 21 \\
Mouth diseases & 17 \\
Ocular diseases & 5 \\
Cardiovascular diseases & 2 \\
Others (only 1 trial each) & 6 \\
\hline
\end{tabular}

operative approaches have been investigated for the ablation of a broad range of solid tumors ${ }^{[22]}$. The first clinical application of PDT for breast cancer treatment was to treat skin metastases recurrence in the chest wall. The protocol tested was using Photofrin, and showed benefits in fifty percentage of the patients ${ }^{[100]}$. Later studies with Photofrin ${ }^{[123]}, \mathrm{m}^{-T_{H P C}}{ }^{[19]}$ and $\mathrm{Npe}^{[124]}$ supported PDT as an effective palliation treatment for chest wall recurrence in breast cancer patients. Further applications for PDT as treatment for breast cancer solid tumor and its sequelae, specifically its role in combination with adjuvant radiotherapy and chemotherapy, are being explored. Regarding the metastatic problem in breast cancer, although this systemic complication represents the most complex challenge in PDT-treatment for this type of tumor, a study conducted with fourteen patients with more than 500 truncal metastases showed that all patients presented tumor necrosis and nine of them demonstrated complete responses ${ }^{[123]}$. Last but not least, a clinical trial of late-stage breast cancer patients treated by a local intervention using an $805 \mathrm{~nm}$ laser for noninvasive irradiation, indocyanine green and an immunoadjuvant (glycated chitosan) for immunological stimulation has shown that the combine therapeutic approach was safer and more efficient for treatment of metastatic breast cancer than each individual strategy ${ }^{[125]}$. This study demonstrated that adjuvant treatment with immunotherapy following PDT may improve its effectiveness and represents a viable future treatment of tumors at distant sites, as discussed before, but still need more clinical studies.

\section{PERSPECTIVES}

There are several other new approaches being tested in "in vitro" and or in pre-clinical models aiming at improving the performance, the homing and delivery of PSs or including mixed formulations of chemotherapeutics in combination with PSs which appeared to show promising results up to now ${ }^{[126,127]}$. The fast development of the field of nanostructurated materials is in part responsible for the great increase of different innovative alternatives and approaches being studied. Of note is the notion that these approaches could also be used as detection and treatment alternatives at the same time supporting the idea that a better outcome could be reached by using these new multitasks tools in a near future. For example, a recent report has described the results of a $\mathrm{pH}$, glutathione (GSH) and hyaluronidase (HAase) triple-responsive nanoplatform for HER2 and CD44 dual-targeted and fluorescence imaging-guided PDT/photothermal therapy (PTT) dual-therapy against HER2-overexpressed breast cancer. The nanoplatform was fabricated by functionalizing gold nanorods (GNRs) with hyaluronic acid (HA) pendant hydrazide and thiolgroups via Au-S bonds, and subsequently chemically conjugating 5-ALA, Cy7.5 and anti-HER2 antibody onto HA moiety for PDT. The final Nano platform bears fluorescent imaging and active targeting capacities, respectively. In this study the authors not only demonstrated that HER2 and CD44 receptors-mediated dualtargeting strategy significantly enhanced the cellular uptake of GNR-HA-ALA/Cy7.5-HER2 but also that the combined PDT/PTT treatment had significantly superior antitumor effect than PDT or PTT alone both in the MCF-7 cells model as well as in pre-clinical studies ${ }^{[128]}$. Additionally, studies performed in human breast derived cell lines have shown that supersaturated hypericin (HYP) encapsulated on Pluronic ${ }^{\circledR} 123$ (HYP/P123) micelles presented high stability and high rates of binding to cells, which resulted in their selective internalization in MCF-7, indicating their potential to permeate the membrane of these cells. Moreover, HYP/P123 micelles accumulated in mitochondria and endoplasmic reticulum organelles inducing 
Table 3. Details of on-going clinical trials with the usage of PDT for handling neoplastic diseases

\begin{tabular}{|c|c|c|c|c|c|}
\hline Indication & Photosensitizer & Study type & $\begin{array}{l}\text { Estimated study } \\
\text { completion date }\end{array}$ & $\begin{array}{c}\text { Estimated } \\
\text { enrollment } \\
\text { (participants) }\end{array}$ & $\begin{array}{l}\text { ClincalTrials. } \\
\text { gov Identifier }\end{array}$ \\
\hline Anal Cancer & Aminolevulinic acid & Interventional & Apr/21 & 12 & NCT02698293 \\
\hline Basal Cell Carcinoma & Aminolevulinic acid & Interventional & Nov/21 & 50 & NCT03467789 \\
\hline Basal Cell Carcinoma & Aminolevulinic acid & Interventional & 01/May/23 & 50 & NCT03483441 \\
\hline Basal Cell Carcinoma & $\begin{array}{l}\text { Aminolevulinic acid } \\
\text { Methyl aminolevulinate }\end{array}$ & Interventional & $\mathrm{Sep} / 20$ & 281 & NCT02144077 \\
\hline Basal Cell Carcinoma & Methyl aminolevulinate & Interventional & 01/Jun/20 & 20 & NCT03167762 \\
\hline $\begin{array}{l}\text { Basal Cell Carcinoma } \\
\text { Basal Cell Neoplasms }\end{array}$ & $\begin{array}{l}\text { Aminolevulinic acid } \\
\text { Methyl aminolevulinate } \\
\text { Hexylaminolevulinate }\end{array}$ & Interventional & $\mathrm{Dec} / 22$ & 117 & NCT02367547 \\
\hline Basal Cell Carcinoma, Superficial & Aminolevulinic acid & Interventional & Aug/24 & 186 & NCT03573401 \\
\hline Brain Tumor, Recurrent & Porfimer sodium & Interventional & Jun/31 & 30 & NCT01966809 \\
\hline Brain Tumor, Recurrent & Porfimer sodium & Interventional & $\mathrm{Apr} / 24$ & 24 & NCT01682746 \\
\hline Breast Cancer, Metastatic & Verteporfin & Interventional & $\mathrm{Dec} / 19$ & 15 & NCT02939274 \\
\hline Cervical Intraepithelial Neoplasia & Aminolevulinic acid & Interventional & Nov/18 & 60 & NCT02631863 \\
\hline Cholangiocarcinoma & Porfimer sodium & Interventional & 22/Mar/18 & 55 & NCT01755013 \\
\hline Cholangiocarcinoma & Porfimer sodium & Interventional & Jul/18 & 39 & NCT02585856 \\
\hline Cholangiocarcinoma & Temoporfin & Interventional & Aug/19 & 20 & NCT03003065 \\
\hline Cholangiocarcinoma & Fimaporfin & Interventional & Aug/19 & 55 & NCT01900158 \\
\hline Cholangiocarcinoma, Hilar & Deuteporfin & Interventional & May/19 & 50 & NCT02955771 \\
\hline Desmoid Tumors & Aminolevulinic acid & Interventional & $\mathrm{Dec} / 26$ & 140 & NCT01898416 \\
\hline $\begin{array}{l}\text { Esophageal Adenocarcinoma, Stages I, II, III } \\
\text { Esophageal Squamous Cell Carcinoma, Stages I, } \\
\text { II, III }\end{array}$ & Porfimer sodium & Interventional & $\mathrm{Dec} / 19$ & 40 & NCT02628665 \\
\hline Esophagogastric Cancer & $\begin{array}{l}\text { Palladium } \\
\text { bacteriopheophorbide }\end{array}$ & Interventional & Apr/19 & 36 & NCT03133650 \\
\hline Glioblastoma & Aminolevulinic acid & Interventional & $\mathrm{Dec} / 19$ & 10 & NCT03048240 \\
\hline $\begin{array}{l}\text { Head and Neck Carcinoma, Recurrent } \\
\text { Head and Neck Carcinoma, Locally Advanced }\end{array}$ & Porfimer sodium & Interventional & 01/Nov/22 & 82 & NCT03727061 \\
\hline Lung Cancer & Porfimer sodium & Interventional & 15/Sep/17 & 10 & NCT03211078 \\
\hline $\begin{array}{l}\text { Lung Cancer } \\
\text { Lung Cancer, Metastatic }\end{array}$ & Porfimer sodium & Interventional & Mar/19 & 10 & NCT03344861 \\
\hline Lung Cancer, Non Small Cell & Porfimer sodium & Interventional & Sep/21 & 66 & NCT03564054 \\
\hline $\begin{array}{l}\text { Lung Cancer, Non Small Cell } \\
\text { Lung Metastasis }\end{array}$ & Porfimer sodium & Interventional & May/19 & 5 & NCT02916745 \\
\hline $\begin{array}{l}\text { Lung Cancer, Non-Small Cell } \\
\text { Mesothelioma, Malignant }\end{array}$ & Porfimer sodium & Interventional & 01/Aug/21 & 12 & NCT03678350 \\
\hline Lung Cancer, Squamous Cell & Chlorin e6-PVP & Interventional & Oct/24 & 111 & NCT03346304 \\
\hline Mesothelioma, Epitheliod Malignant Pleural & Porfimer sodium & Interventional & May/18 & 102 & NCT02153229 \\
\hline Neurofibromatosis & Aminolevulinic acid & Interventional & Nov/18 & 30 & NCT01682811 \\
\hline Neurofibromatosis & Aminolevulinic acid & Interventional & Aug/23 & 30 & NCT02728388 \\
\hline Oral cancer & Aminolevulinic acid & Interventional & 31/May/19 & 30 & NCT03638622 \\
\hline $\begin{array}{l}\text { Oral Cavity Squamous Cell Carcinoma, Stage I } \\
\text { Oral Cavity Squamous Cell Carcinoma, Stage II }\end{array}$ & $\mathrm{HPPH}^{\star}$ & Interventional & 02/Nov/21 & 114 & NCT03090412 \\
\hline Pancreatic Cancer, Non-Resectable & Verteporfin & Interventional & Jan/22 & 15 & NCT03033225 \\
\hline $\begin{array}{l}\text { Pancreatic Cancer, Stage III } \\
\text { Pancreas, Acinar Cell Adenocarcinoma of the } \\
\text { Pancreas, Duct Cell Adenocarcinoma of the }\end{array}$ & Porfimer sodium & Interventional & $31 / \operatorname{Jan} / 20$ & 12 & NCT01770132 \\
\hline Peritoneal Carcinomatosis & $\begin{array}{l}\text { Hypericum perforatum } \\
\text { extract }\end{array}$ & Interventional & $\mathrm{Jul} / 20$ & 50 & NCT02840331 \\
\hline Prostate Cancer, Localized & $\begin{array}{l}\text { Palladium } \\
\text { bacteriopheophorbide }\end{array}$ & Interventional & 01/Mar/24 & 50 & NCT03315754 \\
\hline Prostate Cancer, Recurrent & Verteporfin & Interventional & 31/Dec/20 & 36 & NCT03067051 \\
\hline Skin Cancer, Non-melanoma & Aminolevulinic acid & Interventional & Mar/21 & 20 & NCT02751151 \\
\hline Skin Cancer, Non-melanoma & Aminolevulinic acid & Interventional & $\mathrm{Dec} / 22$ & 40 & NCT02867722 \\
\hline Skin Cancer, Non-melanoma & Aminolevulinic acid & Interventional & 30/Apr/21 & 20 & NCT03110159 \\
\hline Squamous Cell Carcinoma & Aminolevulinic acid & Interventional & $\operatorname{Jan} / 20$ & 40 & NCT03025724 \\
\hline Urothelial Carcinoma, Upper Tract & Palladium & Interventional & Aug/20 & 18 & NCT03617003 \\
\hline
\end{tabular}




\begin{tabular}{|c|c|c|c|c|c|}
\hline Cholangiocarcinoma & Porfimer sodium & Observational & 30/Dec/18 & 200 & NCT01524146 \\
\hline Esophageal Adenocarcinoma, Early & any & Observational & $\mathrm{Jan} / 22$ & 400 & NCT00587314 \\
\hline Lung Cancer & Porfimer sodium & Observational & $30 / \mathrm{Dec} / 24$ & 1000 & NCT01842555 \\
\hline Lung Cancer & any & Observational & 15/Dec/23 & 1000 & NCT03589456 \\
\hline Neoplastic Disease & any & Observational & $\mathrm{Jul} / 21$ & 400 & NCT02159742 \\
\hline Prostate Cancer & any & Observational & 01/Mar/20 & 200 & NCT03492424 \\
\hline
\end{tabular}

${ }^{\star} \mathrm{HPPH}$ stands for 2-1[Heyloxyethyl]-2-Devinylpyropheophorbide-a

photodynamic cell death by necrosis and selective time- and dose dependent phototoxic effects on MCF-7 cells but little damage to non-tumorigenic cells. The micelles inhibited the generation of cellular colonies as well as migration of tumor cells indicating possible capacity to prevent the recurrence of breast cancer and to minimize the chances of cell spreading and thus the formation of metastases ${ }^{[129]}$.

Although PDT is based on the preferential accumulation in the tumor tissue, this selectivity is not absolute and some damage can occur to the surrounding tissue. Thus, a deeper understanding of the molecular mechanisms involved in drug delivery and specific targeting of tumors should contribute to the development of more specific technologies to deliver light and/or drugs to the tumor site and also to minimize resistance to PDT. Accordingly, the development of new PS targeting specific tumor sites have led to the modality of targeted-PDT ${ }^{[130]}$. Another approach consists the photochemical delivery of drugs through photochemical internalization (PCI), a modified form of PDT. PCI is actually a light-controlled drug-delivery alternative in which light activation enables spatiotemporal specificity and control of the intracellular drug release ${ }^{[131-133]}$. Moreover the potential of PCI to circumvent the resistance and increase the efficacy of a variety of anticancer agents, have been demonstrated in several tumor models including approaches to overcome PDTresistance in breast cancer cells ${ }^{[133,134]}$. Since identifying cellular resistance mechanisms by understanding the differences in cell response at the molecular level is of fundamental importance to improving the protocol and to increase the success of the therapy ${ }^{[135]}$, we have recently shown that breast cancer cells are differently affected by methylene blue (MB) concentrations at the same light dose in MB-PDT and that non-malignant human breast cells are significantly more resistant to the therapy compared to the malignant ones ${ }^{[26]}$. One more example of how the use of a targeting agent would ideally improve the selectivity of PDT for the tumor tissue has been shown in a recent study. By using polyethylene glycol-coated, folate conjugated, benzoporphyrin derivative-loaded liposomes for PDT treatment of breast cancer cells, the researchers have reported that these liposomes are targeted for are greater uptake into TNBC cancer cells ${ }^{[136]}$. Therefore, focusing on the molecular differences of cell death mechanisms induced by PDT, starting with an optimized PS choice and conditions of its delivery and activation, will certainly provide valuable clues for the development of new therapeutic strategies aiming at improving the efficacy of PDT against cancer cells ${ }^{[7,15]}$.

\section{CONCLUSION}

The challenges in fighting the disease rely on intrinsic tumor resistance properties, molecular heterogeneity, and metastasis. Considering all the information provided one can conclude that there are almost no doubts that one relevant advantage of PDT over other cancer treatments is the possibility of generating less side effects to the patients.

In summary, in this review we have explored and presented a broad up-date on the use of PDT as a therapeutic approach in the treatment of primary cancer as well as metastasis. We have covered several topics ranging from the photochemical mechanisms involved, the different cell death mechanisms being triggered by several photosensitizers up to the more recent-on-going clinical trials. Additionally, we have presented a significant amount of information underscoring the relevance of PDT as an alternative therapeutic approach capable of inducing several mechanisms of cell death, some of them simultaneously. 
This capacity could be an interesting way of overcoming the problem of death resistance displayed by many tumors since one of the characteristics that is important for an alternative therapy for cancer treatment is to broaden the spectrum of cell death mechanisms being gathered in order to by-pass the different resistance mechanisms displayed by malignant cells.

Finally, even if more research is still needed in the field including the development and optimization of PS synthesis in order to increase the efficiency on specific tumor cell damage, light sources and irradiation protocols, it is evident that in the majority of the cases, PDT represents a suitable therapeutic alternative presenting several advantages over the traditional clinical approaches for cancer treatments. It is clear that PDT deserves more opportunities and investment in clinical trials. By doing so, it could be expected that the increase in the number of clinical studies with metastatic or non-mestastatic cancer, in the near future, could allow the scientific and clinical community to make more robust conclusions about PDT's real translational potential to become a standard first-line therapy, either alone or in combination with other treatments, for a wide variety of tumors.

\section{DECLARATIONS}

\section{Authors' contributions}

Responsible for the paper: Baptista MS, Labriola L

Concept, design, definition of intellectual content: dos Santos AF, Baptista MS, Labriola L

Literature search, manuscript preparation and revision: dos Santos AF, de Almeida DRQ, Terra LF, Baptista MS, Labriola L

Manuscript editing: dos Santos AF, Labriola L

\section{Availability of data and materials}

Not applicable.

\section{Financial support and sponsorship}

This work was supported by CAPES, CNPq and FAPESP (2017/03618-6; 2016/04676-7 and 2013/07937-8).

\section{Conflicts of interest}

All authors declared that there are no conflicts of interest.

\section{Ethical approval and consent to participate}

Not applicable.

\section{Consent for publication}

Not applicable.

\section{Copyright}

(c) The Author(s) 2019.

\section{REFERENCES}

1. Minn AJ, Gupta GP, Siegel PM, Bos PD, Shu W, et al. Genes that mediate breast cancer metastasis to the brain. Nature 2009;436:518-24.

2. Weigelt B, Peterse JL, van 't Veer LJ. Breast cancer metastasis: markers and models. Nat Rev Cancer 2005;5:591-602.

3. Peinado H, Zhang H, Matei IR, Costa-Silva B, Hoshino A, et al. Pre-metastatic niches: Organ-specific homes for metastases. Nat Rev Cancer 2017;17:302-17.

4. Real PJ, Sierra A, De Juan A, Segovia JC, Lopez-Vega JM, et al. Resistance to chemotherapy via Stat3-dependent overexpression of Bcl-2 in metastatic breast cancer cells. Oncogene 2002;21:7611-8.

5. Daniell MD, Hill JS. A history of photodynamic therapy. Aust N Z J Surg 1991;61:340-8. 
6. Ackroyd R, Kelty C, Brown N, Reed M. The history of photodetection and photodynamic therapy. Photochem Photobiol 2001;74:656-69.

7. Kou J, Dou D, Yang L. Porphyrin photosensitizers in photodynamic therapy and its applications. Oncotarget 2017;8:81591-603.

8. Rizvi I, Celli JP, Evans CL, Abu-Yousif AO, Muzikansky A, et al. Synergistic enhancement of carboplatin efficacy with photodynamic therapy in a three-dimensional model for micrometastatic ovarian cancer. Cancer Res 2010;70:9319-28.

9. Ahn TG, Lee BR, Choi EY, Kim DW, Han SJ. Photodynamic therapy for breast cancer in a BALB/c mouse model. J Gynecol Oncol 2012;23:115-9.

10. Montazerabadi AR, Sazgarnia A, Bahreyni-Toosi MH, Ahmadi A, Shakeri-Zadeh A, et al. Mitoxantrone as a prospective photosensitizer for photodynamic therapy of breast cancer. Photodiagnosis Photodyn Ther 2012;9:46-51.

11. Agostinis P, Buytaert E, Breyssens H, Hendrickx N. Regulatory pathways in photodynamic therapy induced apoptosis. Photochem Photobiol Sci 2004;3:721-9.

12. Casas A, Di Venosa G, Hasan T, Al Batlle. Mechanisms of resistance to photodynamic therapy. Curr Med Chem 2011;18:2486-515.

13. Klotz LO, Kröncke KD, Sies H. Singlet oxygen-induced signaling effects in mammalian cells. Photochem Photobiol Sci 2003;2:88-94.

14. Oleinick NL, Morris RL, Nieminen A. Photodynamic Therapy-Induced Apoptosis. Apoptosis, Senescence, and Cancer; 2007. pp. 557-78.

15. Bacellar IOL, Tsubone TM, Pavani C, Baptista MS. Photodynamic efficiency: from molecular photochemistry to cell death. Int J Mol Sci 2015;16:20523-59.

16. Jensen TJ, Vicente MGH, Luguya R, Norton J, Fronczek FR, et al. Effect of overall charge and charge distribution on cellular uptake, distribution and phototoxicity of cationic porphyrins in HEp2 cells. J Photochem Photobiol B Biol 2010;100:100-11.

17. Pavani C, Iamamoto Y, Baptista MS. Mechanism and efficiency of cell death of type II photosensitizers: effect of zinc chelation. Photochem Photobiol 2012;88:774-81.

18. Bacellar IOL, Oliveira MC, Dantas LS, Costa EB, Junqueira HC, et al. Photosensitized membrane permeabilization requires contactdependent reactions between photosensitizer and lipids. J Am Chem Soc 2018;140:9606-15.

19. Mang TS, Allison R, Hewson G, Snider W, Moskowitz R. A phase II/III clinical study of tin ethyl etiopurpurin (Purlytin)-induced photodynamic therapy for the treatment of recurrent cutaneous metastatic breast cancer. Cancer J Sci Am 1998;4:378-84

20. Anand S, Ortel BJ, Pereira SP, Hasan T, Maytin EV. Biomodulatory approaches to photodynamic therapy for solid tumors. Cancer Lett 2012;326:8-16.

21. Banerjee SM, MacRobert AJ, Mosse CA, Periera B, Bown SG, et al. Photodynamic therapy: inception to application in breast cancer. Breast 2017;31:105-13.

22. Lamberti MJ, Vittar NBR, Rivarola VA. Breast cancer as photodynamic therapy target: Enhanced therapeutic efficiency by overview of tumor complexity. World J Clin Oncol 2014;5:901.

23. Kwiatkowski S, Knap B, Przystupski D, Saczko J, Kędzierska E, et al. Photodynamic therapy - mechanisms, photosensitizers and combinations. Biomed Pharmacother 2018;106:1098-107.

24. Abo-Zeid MAM, Abo-Elfadl MT, Mostafa SM. Photodynamic therapy using 5-aminolevulinic acid triggered DNA damage of adenocarcinoma breast cancer and hepatocellular carcinoma cell lines. Photodiagnosis Photodyn Ther 2018;21:351-6.

25. Tardivo JP, Del Giglio A, de Oliveira CS, Gabrielli DS, Junqueira HC, et al. Methylene blue in photodynamic therapy: From basic mechanisms to clinical applications. Photodiagnosis Photodyn Ther 2005;2:175-91.

26. Dos Santos AF, Terra LF, Wailemann RAM, Oliveira TC, Gomes VDM, et al. Methylene blue photodynamic therapy induces selective and massive cell death in human breast cancer cells. BMC Cancer 2017;17:194.

27. Delaey E, van Laar F, De Vos D, Kamuhabwa A, Jacobs P, et al. A comparative study of the photosensitizing characteristics of some cyanine dyes. J Photochem Photobiol B 2000;55:27-36.

28. Garg AD, Krysko D V, Vandenabeele P, Agostinis P. Hypericin-based photodynamic therapy induces surface exposure of damage-associated molecular patterns like HSP70 and calreticulin. Cancer Immunol Immunother 2012;61:215-21.

29. Panzarini E, Inguscio V, Fimia GM, Dini L. Rose Bengal acetate photodynamic therapy (RBAc-PDT) induces exposure and release of damage-associated molecular patterns (DAMPs) in human HeLa cells. PLoS One 2014;9:e105778.

30. Agostinis P, Berg K, Cengel KA, Foster TH, Girotti AW, et al. Photodynamic therapy of cancer: an update. CA Cancer J Clin 2011;61:250-81.

31. Cramers P, Ruevekamp M, Oppelaar H, Dalesio O, Baas P, et al. Foscan uptake and tissue distribution in relation to photodynamic efficacy. Br J Cancer 2003;88:283-90.

32. Zheng X, Morgan J, Pandey SK, Chen Y, Tracy E, et al. Conjugation of 2-(1'-hexyloxyethyl)-2-devinylpyropheophorbide-a (HPPH) to carbohydrates changes its subcellular distribution and enhances photodynamic activity in vivo. J Med Chem 2009;52:4306-18.

33. Pogue BW, Ortel B, Chen N, Redmond RW, Hasan T. A photobiological and photophysical-based study of phototoxicity of two chlorins. Cancer Res 2001;61:717-24.

34. Chen Z, Woodburn KW, Shi C, Adelman DC, Rogers C, et al. Photodynamic therapy with motexafin lutetium induces redox-sensitive apoptosis of vascular cells. Arterioscler Thromb Vasc Biol 2001;21:759-64.

35. Spring BQ, Rizvi I, Xu N, Hasan T. The role of photodynamic therapy in overcoming cancer drug resistance. Photochem Photobiol Sci 2015;14:1476-91.

36. Josefsen LB, Boyle RW. Unique diagnostic and therapeutic roles of porphyrins and phthalocyanines in photodynamic therapy, imaging and theranostics. Theranostics 2012;2:916-66.

37. Sandland J, Malatesti N, Boyle R. Porphyrins and related macrocycles: combining photosensitization with radio- or optical-imaging for next generation theranostic agents. Photodiagnosis Photodyn Ther 2018;23:281-94.

38. Tsubone TM, Martins WK, Pavani C, Junqueira HC, Itri R, et al. Enhanced efficiency of cell death by lysosome-specific photodamage. Sci Rep 2017;7:6734.

39. Galluzzi L, Vitale I, Aaronson SA, Abrams JM, Adam D, et al. Molecular mechanisms of cell death: recommendations of the nomenclature committee on cell death 2018. Cell Death Differ 2018;25:486-541. 
40. van Straten D, Mashayekhi V, de Bruijn HS, Oliveira S, Robinson DJ. Oncologic photodynamic therapy: basic principles, current clinical status and future directions. Cancers (Basel) 2017;9:1-54.

41. Kessel D. Death pathways associated with photodynamic therapy. Med Laser Appl 2006;21:219-24.

42. Kerr JF, Wyllie AH, Currie AR. Apoptosis: a basic biological phenomenon with wide-ranging implications in tissue kinetics. Br J Cancer 1972;26:239-57.

43. Tait SWG, Green DR. Mitochondria and cell death: outer membrane permeabilization and beyond. Nat Rev Mol Cell Biol 2010;11:621-32.

44. Jost PJ, Grabow S, Gray D, McKenzie MD, Nachbur U, et al. XIAP discriminates between type i and type II FAS-induced apoptosis. Nature 2009;460:1035-9.

45. Shamas-Din A, Kale J, Leber B, Andrews DW. Mechanisms of action of Bcl-2 family proteins. Cold Spring Harb Perspect Biol 2013;5:a008714.

46. Moldoveanu T, Follis AV, Kriwacki RW, Green DR. Many players in BCL-2 family affairs. Trends Biochem Sci 2014;39:101-11.

47. Galluzzi L, Kepp O, Kroemer G. Mitochondrial regulation of cell death: a phylogenetically conserved control. Microb Cell 2016;3:101-8.

48. Huang K, Zhang J, O’Neill KL, Gurumurthy CB, Quadros RM, et al. Cleavage by caspase 8 and mitochondrial membrane association activate the BH3-only protein bid during TRAIL-induced apoptosis. J Biol Chem 2016;291:11843-51.

49. Vandenabeele P, Galluzzi L, Vanden Berghe T, Kroemer G. Molecular mechanisms of necroptosis: an ordered cellular explosion. Nat Rev Mol Cell Biol 2010;11:700-14.

50. Boya P, Kroemer G. Lysosomal membrane permeabilization in cell death. Oncogene 2008;27:6434-51.

51. Wang F, Gómez-Sintes R, Boya P. Lysosomal membrane permeabilization and cell death. Traffic 2018;19:918-31.

52. Oliveira CS, Turchiello R, Kowaltowski AJ, Indig GL, Baptista MS. Major determinants of photoinduced cell death: subcellular localization versus photosensitization efficiency. Free Radic Biol Med 2011;51:824-33.

53. Kessel D, Reiners JJ. Promotion of proapoptotic signals by lysosomal photodamage. Photochem Photobiol 2016;91:931-6.

54. Feng X, Shi Y, Xie L, Zhang K, Wang X, et al. Synthesis, characterization, and biological evaluation of a porphyrin-based photosensitizer and its isomer for effective photodynamic therapy against breast cancer. J Med Chem 2018;61:7189-201.

55. Abrahamse H, Hamblin MR. New photosensitizers for photodynamic therapy. Biochem J 2016;473:347-64.

56. Kushibiki T, Hirasawa T, Okawa S, Ishihara M. Responses of cancer cells induced by photodynamic therapy. J Healthc Eng 2013;4:87-108.

57. Reiners JJ, Agostinis P, Berg K, Oleinick NL, Kessel D. Assessing autophagy in the context of photodynamic therapy. Autophagy 2010;6:7-18.

58. Galluzzi L, Bravo-San Pedro JM, Kroemer G. Organelle-specific initiation of cell death. Nat Cell Biol 2014;16:728-36.

59. Coupienne I, Fettweis G, Rubio N, Agostinis P, Piette J. 5-ALA-PDT induces RIP3-dependent necrosis in glioblastoma. Photochem Photobiol Sci 2011;10:1868-78.

60. Mrschtik M, Ryan KM. Lysosomal proteins in cell death and autophagy. FEBS J 2015;282:1858-70.

61. Zou J, Kawai T, Tsuchida T, Kozaki T, Tanaka H, et al. Poly IC triggers a cathepsin D- and IPS-1-dependent pathway to enhance cytokine production and mediate dendritic cell necroptosis. Immunity 2013;38:717-28.

62. Dixon SJ, Lemberg KM, Lamprecht MR, Skouta R, Zaitsev EM, et al. Ferroptosis : an iron-dependent form of nonapoptotic cell death. Cell 2012;149:1060-72.

63. Garg AD, Agostinis P. ER stress, autophagy and immunogenic cell death in photodynamic therapy-induced anti-cancer immune responses. Photochem Photobiol Sci 2014;13:474-87.

64. Acedo P, Stockert JC, Cañete M, Villanueva A. Two combined photosensitizers: a goal for more effective photodynamic therapy of cancer. Cell Death Dis 2014;5:e1122.

65. Tanaka M, Kataoka H, Yano S, Sawada T, Akashi H, et al. Immunogenic cell death due to a new photodynamic therapy (PDT) with glycoconjugated chlorin (G-chlorin). Oncotarget 2016;7:47242-51.

66. Pizova K, Tomankova K, Daskova A, Binder S, Bajgar R, et al. Photodynamic therapy for enhancing antitumour immunity. Biomed Pap Med Fac Univ Palacky Olomouc Czech Repub 2012;156:93-102.

67. Showalter A, Limaye A, Oyer JL, Igarashi R, Kittipatarin C, et al. Cytokines in immunogenic cell death: applications for cancer immunotherapy. Cytokine 2017;97:123-32.

68. Zitvogel L, Galluzzi L, Smyth MJ, Kroemer G. Mechanism of action of conventional and targeted anticancer therapies: reinstating immunosurveillance. Immunity 2013;39:74-88.

69. Hanahan D, Weinberg RA. Hallmarks of cancer: the next generation. Cell 2011;144:646-74.

70. Garg AD, Maes H, Romano E, Agostinis P. Autophagy, a major adaptation pathway shaping cancer cell death and anticancer immunity responses following photodynamic therapy. Photochem Photobiol Sci 2015;14:1410-24.

71. Krysko D V, Garg AD, Kaczmarek A, Krysko O, Agostinis P, et al. Immunogenic cell death and DAMPs in cancer therapy. Nat Rev Cancer 2012;12:860-75.

72. Inoue H, Tani K. Multimodal immunogenic cancer cell death as a consequence of anticancer cytotoxic treatments. Cell Death Differ 2014;21:39-49.

73. Garg AD, Maes H, van Vliet AR, Agostinis P. Targeting the hallmarks of cancer with therapy-induced endoplasmic reticulum (ER) stress. Mol Cell Oncol 2015;2:e975089.

74. Garg AD, Dudek AM, Agostinis P. Cancer immunogenicity, danger signals, and DAMPs: what, when, and how? Biofactors 2013;39:355-67.

75. Garg AD, Dudek AM, Ferreira GB, Verfaillie T, Vandenabeele P, et al. ROS-induced autophagy in cancer cells assists in evasion from determinants of immunogenic cell death. Autophagy 2013;9:1292-307.

76. Shams M, Owczarczak B, Manderscheid-Kern P, Bellnier DA, Gollnick SO. Development of photodynamic therapy regimens that control primary tumor growth and inhibit secondary disease. Cancer Immunol Immunother 2015;64:287-97.

77. Henderson BW, Gollnick SO, Snyder JW, Busch TM, Kousis PC, et al. Choice of oxygen-conserving treatment regimen determines the inflammatory response and outcome of photodynamic therapy of tumors. Cancer Res 2004;64:2120-6. 
78. Gollnick SO, Vaughan L, Henderson BW. Generation of effective antitumor vaccines using photodynamic therapy. Cancer Res 2002;62:1604-8.

79. Garg AD, Elsen S, Krysko DV, Vandenabeele P, de Witte P, et al. Resistance to anticancer vaccination effect is controlled by a cancer cellautonomous phenotype that disrupts immunogenic phagocytic removal. Oncotarget 2015;6:26841-60.

80. D'Cruz AK, Robinson MH, Biel MA. mTHPC-mediated photodynamic therapy in patients with advanced, incurable head and neck cancer: a multicenter study of 128 patients. Head Neck 2004;26:232-40.

81. Hopper C, Niziol C, Sidhu M. The cost-effectiveness of Foscan mediated photodynamic therapy (Foscan-PDT) compared with extensive palliative surgery and palliative chemotherapy for patients with advanced head and neck cancer in the UK. Oral Oncol 2004;40:372-82.

82. Huang Z, Xu H, Meyers AD, Musani AI, Wang L, et al. Photodynamic therapy for treatment of solid tumors--potential and technical challenges. Technol Cancer Res Treat 2008;7:309-20.

83. Egeblad M, Nakasone ES, Werb Z. Tumors as organs: complex tissues that interface with the entire organism. Dev Cell 2010;18:884-901.

84. Pogue BW, Elliott JT, Kanick SC, Davis SC, Samkoe KS, et al. Revisiting photodynamic therapy dosimetry: reductionist \& surrogate approaches to facilitate clinical success. Phys Med Biol 2016;61:R57-89.

85. Mallidi S, Anbil S, Bulin AL, Obaid G, Ichikawa M, et al. Beyond the barriers of light penetration: strategies, perspectives and possibilities for photodynamic therapy. Theranostics 2016;6:2458-87.

86. Schweitzer C, Schmidt R. Physical mechanisms of generation and deactivation of singlet oxygen. Chem Rev 2003;103:1685-757.

87. Lovell JF, Liu TWB, Chen J, Zheng G. Activatable photosensitizers for imaging and therapy. Chem Rev 2010;110:2839-57.

88. Dang J, He H, Chen D, Yin L. Manipulating tumor hypoxia toward enhanced photodynamic therapy (PDT). Biomater Sci 2017;5:1500-11.

89. Sitnik TM, Hampton JA, Henderson BW. Reduction of tumour oxygenation during and after photodynamic therapy in vivo: effects of fluence rate. Br J Cancer 1998;77:1386-94.

90. Penjweini R, Kim MM, Finlay JC, Zhu TC. Investigating the impact of oxygen concentration and blood flow variation on photodynamic therapy. Proc SPIE Int Soc Opt Eng 2016;9694:1-13.

91. Turan IS, Yildiz D, Turksoy A, Gunaydin G, Akkaya EU. A bifunctional photosensitizer for enhanced fractional photodynamic therapy: singlet oxygen generation in the presence and absence of light. Angew Chem Int Ed Engl 2016;55:2875-8.

92. Protti S, Albini A, Viswanathan R, Greer A. Targeting photochemical scalpels or lancets in the photodynamic therapy field-the Photochemist's role. Photochem Photobiol 2017;93:1139-53.

93. Stringasci MD, Fortunato TC, Moriyama LT, Filho JDV, Bagnato VS, et al. Interstitial PDT using diffuser fiber-investigation in phantom and in vivo models. Lasers Med Sci 2017;32:1009-16.

94. Kessel D, Reiners JJ. Enhanced efficacy of photodynamic therapy via a sequential targeting protocol. Photochem Photobiol 2014;90:889-95

95. Cincotta L, Szeto D, Lampros E, Hasan T, Cincotta AH. Benzophenothiazine and benzoporphyrin derivative combination phototherapy effectively eradicates large murine sarcomas. Photochem Photobiol 1996;63:229-37.

96. Ang JM, Riaz I Bin, Kamal MU, Paragh G, Zeitouni NC. Photodynamic therapy and pain: a systematic review. Photodiagnosis Photodyn Ther 2017;19:308-44.

97. Tardivo JP, Adami F, Correa JA, Pinhal MAS, Baptista MS. A clinical trial testing the efficacy of PDT in preventing amputation in diabetic patients. Photodiagnosis Photodyn Ther 2014;11:342-50.

98. Zhu S, Zhang Q, Sun X, Zeh HJ, Lotze MT, et al. HSPA5 regulates ferroptotic cell death in cancer cells. Cancer Res 2017;77:2064-77.

99. Eckhardt BL, Francis PA, Parker BS, Anderson RL. Strategies for the discovery and development of therapies for metastatic breast cancer. Nat Rev Drug Discov 2012;11:479-97.

100. Khan SA, Dougherty TJ, Mang TS. An evaluation of photodynamic therapy in the management of cutaneous metastases of breast cancer. Eur J Cancer 1993;29A:1686-90.

101. Montazerabadi AR, Sazgarnia A, Bahreyni-toosi MH, Ahmadi A, Aledavood A. The effects of combined treatment with ionizing radiation and indocyanine green-mediated photodynamic therapy on breast cancer cells. J Photochem Photobiol B Biol 2012;109:42-9.

102. Lo VCK, Akens MK, Moore S, Yee AJM, Wilson BC, et al. Beyond radiation therapy: photodynamic therapy maintains structural integrity of irradiated healthy and metastatically involved vertebrae in a pre-clinical in vivo model. Breast Cancer Res Treat 2012;135:391-401.

103. Lo VCK, Akens MK, Wise-Milestone L, Yee AJM, Wilson BC, et al. The benefits of photodynamic therapy on vertebral bone are maintained and enhanced by combination treatment with bisphosphonates and radiation therapy. J Orthop Res 2013;31:1398-405.

104. Crescenzi E, Varriale L, Iovino M, Chiaviello A, Veneziani BM, et al. Photodynamic therapy with indocyanine green complements and enhances low-dose cisplatin cytotoxicity in MCF-7 breast cancer cells. Mol Cancer Ther 2004;3:537-44.

105. Zimmermann A, Walt H, Haller U, Baas P, Klein SD. Effects of chlorin-mediated photodynamic therapy combined with fluoropyrimidines in vitro and in a patient. Cancer Chemother Pharmacol 2003;51:147-54.

106. Aniogo EC, George BPA, Abrahamse H. In vitro combined effect of Doxorubicin and sulfonated zinc Phthalocyanine-mediated photodynamic therapy on MCF-7 breast cancer cells. Tumour Biol 2017;39:1010428317727278.

107. Tong Z, Miao P, Liu T, Jia Y, Liu X. Enhanced antitumor effects of BPD-MA-mediated photodynamic therapy combined with adriamycin on breast cancer in mice. Acta Pharmacol Sin 2012;33:1319-24.

108. Tsuchihashi T, Mori K, Ueyama K, Yoneya S. Five-year results of photodynamic therapy with verteporfin for Japanese patients with neovascular age-related macular degeneration. Clin Ophthalmol 2013;7:615-20.

109. Pece A, Milani P, Isola V, Pierro L. A long-term study of photodynamic therapy with verteporfin for choroidal neovascularization at the edge of chorioretinal atrophy in pathologic myopia. Ophthalmologica 2011;225:161-8.

110. Dougherty TJ, Gomer CJ, Henderson BW, Jori G, Kessel D, et al. Photodynamic therapy. J Natl Cancer Inst 1998;90:889-905.

111. Allison RR, Sibata CH. Oncologic photodynamic therapy photosensitizers: a clinical review. Photodiagnosis Photodyn Ther 2010;7:61-75.

112. Breskey JD, Lacey SE, Vesper BJ, Paradise WA, Radosevich JA, et al. Photodynamic therapy: occupational hazards and preventative recommendations for clinical administration by healthcare providers. Photomed Laser Surg 2013;31:398-407. 
113. Schweitzer VG. PHOTOFRIN-mediated photodynamic therapy for treatment of early stage oral cavity and laryngeal malignancies. Lasers Surg Med 2001;29:305-13.

114. Stoodley M, Sikorski JM. Objective and useful mobility assessment of patients with arthropathy of the hip and knee. Clin Orthop Relat Res 1987;1:110-6.

115. Lou PJ, Jäger HR, Jones L, Theodossy T, Bown SG, et al. Interstitial photodynamic therapy as salvage treatment for recurrent head and neck cancer. Br J Cancer 2004;91:441-6.

116. Story W, Sultan AA, Bottini G, Vaz F, Lee G, et al. Strategies of airway management for head and neck photo-dynamic therapy. Lasers Surg Med 2013;45:370-6.

117. Bown SG, Rogowska AZ, Whitelaw DE, Lees WR, Lovat LB, et al. Photodynamic therapy for cancer of the pancreas. Gut 2002;50:549-57.

118. Pereira SP, Ayaru L, Rogowska A, Mosse A, Hatfield ARW, et al. Photodynamic therapy of malignant biliary strictures using mesotetrahydroxyphenylchlorin. Eur J Gastroenterol Hepatol 2007;19:479-85.

119. Wyss P, Schwarz V, Dobler-Girdziunaite D, Hornung R, Walt H, et al. Photodynamic therapy of locoregional breast cancer recurrences using a chlorin-type photosensitizer. Int J cancer 2001;93:720-4.

120. Moore CM, Nathan TR, Lees WR, Mosse CA, Freeman A, et al. Photodynamic therapy using meso tetra hydroxy phenyl chlorin (mTHPC) in early prostate cancer. Lasers Surg Med 2006;38:356-63.

121. Nathan TR, Whitelaw DE, Chang SC, Lees WR, Ripley PM, et al. Photodynamic therapy for prostate cancer recurrence after radiotherapy: a phase I study. J Urol 2002;168:1427-32.

122. Baskaran R, Lee J, Yang SG. Clinical development of photodynamic agents and therapeutic applications. Biomater Res 2018;22:25.

123. Cuenca RE, Allison RR, Sibata C, Downie GH. Breast cancer with chest wall progression: treatment with photodynamic therapy. Ann Surg Oncol 2004;11:322-7.

124. Taber SW, Fingar VH, Coots CaT, Wieman TJ. Photodynamic therapy using mono-L-aspartyl chlorin e6 (Npe6) for the treatment of cutaneous disease: a phase I clinical study. Clin Cancer Res 1998;4:2741-6.

125. Li X, Ferrel GL, Guerra MC, Hode T, Lunn JA, et al. Preliminary safety and efficacy results of laser immunotherapy for the treatment of metastatic breast cancer patients. Photochem Photobiol Sci 2011;10:817-21.

126. Mfouo-Tynga I, Houreld NN, Abrahamse H. Evaluation of cell damage induced by irradiated Zinc-Phthalocyanine-gold dendrimeric nanoparticles in a breast cancer cell line. Biomed J 2018;41:254-64.

127. Yang Y, Yang X, Li H, Li C, Ding H, et al. Near-infrared light triggered liposomes combining photodynamic and chemotherapy for synergistic breast tumor therapy. Colloids Surfaces B Biointerfaces 2019;173:564-70.

128. Xu W, Qian J, Hou G, Wang Y, Wang J, et al. A dual-targeted hyaluronic acid-gold nanorod platform with triple-stimuli responsiveness for photodynamic/photothermal therapy of breast cancer. Acta Biomater 2018;83:400-13.

129. Damke GMZF, Souza RP, Montanha MC, Damke E, Gonçalves RS, et al. Selective photodynamic effects on breast cancer cells provided by P123 Pluronic $囚-b a s e d$ nanoparticles modulating hypericin delivery. Anticancer Agents Med Chem 2018; doi: 10.2174/18715206186661811 02091010 .

130. Hodgkinson N, Kruger CA, Abrahamse H. Targeted photodynamic therapy as potential treatment modality for the eradication of colon cancer and colon cancer stem cells. Tumour Biol 2017;39:1010428317734691.

131. Theodossiou TA, Gonçalves AR, Yannakopoulou K, Skarpen E, Berg K. Photochemical internalization of tamoxifens transported by a "Trojan-horse" nanoconjugate into breast-cancer cell lines. Angew Chem Int Ed Engl 2015;54:4885-9.

132. Eng MS, Kaur J, Prasmickaite L, Engesæter BØ, Weyergang A, et al. Enhanced targeting of triple-negative breast carcinoma and malignant melanoma by photochemical internalization of CSPG4-targeting immunotoxins. Photochem Photobiol Sci 2018;17:539-51.

133. Norum O, Kristian P, Weyergang A, Giercksky K, Berg K. Photochemical internalization (PCI ) in cancer therapy: from bench towards bedside medicine. J Photochem Photobiol B Biol 2009;96:83-92.

134. Olsen CE, Weyergang A, Edwards VT, Berg K, Brech A, et al. Development of resistance to photodynamic therapy (PDT) in human breast cancer cells is photosensitizer-dependent: possible mechanisms and approaches for overcoming PDT-resistance. Biochem Pharmacol 2017; 144:63-77.

135. Broekgaarden M, Weijer R, van Gulik TM, Hamblin MR, Heger M. Tumor cell survival pathways activated by photodynamic therapy: a molecular basis for pharmacological inhibition strategies. Cancer Metastasis Rev 2015;34:643-90.

136. Sneider A, Jadia R, Piel B, VanDyke D, Tsiros C, et al. Engineering remotely triggered liposomes to target triple negative breast cancer. Oncomedicine 2017;2:1-13. 